Brit. J. industr. Med., 1963, 20, 124.

\title{
ESTIMATING PROGRESSION OF COAL-WORKERS' SIMPLE PNEUMOCONIOSIS FROM READINGS OF RADIOLOGICAL CATEGORIES
}

\author{
BY \\ M. E. WISE* and P. D. OLDHAM \\ From the Department of Social Medicine, Oxford University, 8 Keble Road, Oxford, \\ and the Pneumoconiosis Research Unit, Llandough Hospital, Penarth, Glamorgan
}

(RECEIVED FOR PUBLICATION APRIL 5, 1962)

The 1950 I.L.O. classification of radiological abnormality in simple pneumoconiosis describes four discrete categories, but the actual amount of abnormality in an individual does not change by discrete steps. Radiological progression is the increase of a continuous variable, and methods of measuring it must deal with three problems: (1) the coarse classification into discrete categories; (2) possible variation in the rate of an individual's progression from point to point on the continuum of abnormality; (3) the possible non-uniformity of the continuum in relation to some relevant change in the lungs.

The methods proposed for measuring progression were developed from an analysis of two surveys, two and a half years apart, of 689 coal-face workers in eight pits. Some results from a third survey five and a half years after the second are also used. The merits of different methods of film reading are considered. Smooth curves were fitted to the distributions of abnormality found at each survey of each pit, and the progression of the first smooth curve into the second was estimated by the new method of "percentile pairing". The amount of progression within category 1 was found to be about double that in category 2 in all the pits. A new scale of abnormality was derived that makes this change more nearly uniform all along the continuum, and a single index was thus obtained for comparing one pit with another. Progression was also measured on the dust retention scale of Rivers, Wise, King, and Nagelschmidt (1960) and again was greater throughout category 1 than throughout category 2, so that in terms of dust retention progression is not uniform at different points in the continuum of radiological abnormality.

Various implications of the new methods and other approaches to the analysis of progression data are critically discussed.

\section{Part I: General}

Miners working continually in a dusty atmosphere are liable to show increasing radiological evidence of simple pneumoconiosis. In the early stages they appear to suffer little disability or loss of expectation of life. In the later stages of simple pneumoconiosis, again determined radiologically, they may suffer some disability and an appreciable risk of developing complicated pneumoconiosis (Gilson, HughJones, Oldham, and Meade, 1955; Carpenter, Cochrane, Gilson, and Higgins, 1956; Higgins,

*Present address: University Physiology Laboratory, Leiden, Holland
Oldham, Cochrane, and Gilson, 1956; Higgins, Cochrane, Gilson, and Wood, 1959; Cochrane, Higgins, and Thomas, 1961; Cochrane, 1962; Cochrane, Carpenter, Thomas, and Moore, 1963). The main object of studying radiological progression is therefore to estimate how quickly the increase is taking place in the lungs of these men, and then if possible to determine what concentrations of different kinds of dust are safe. In this context a safe concentration of dust is one which is low enough to lead to no progression to the higher stages, even after being breathed for many years.

At present simple pneumoconiosis in a lung can only be recognized and measured during life in terms 
of radiological change of a particular kind. The most frequently used scale of measurement in the U.K. is the one agreed by the I.L.O. International Radiological Classification (International Labour Organisation, 1953), which consists of four categories $0,1,2$, and 3 . The scale is coarse and the boundaries between the grades are, inevitably, arbitrary.* Yet experienced observers are usually consistent when they assess films on this kind of scale, and it is not desirable or practicable to try to change to another one. What is really needed is a more meaningful concept of progression than the simple one of a change from one category to another, together with more precise methods of estimating and measuring this progression. The main purpose of this paper is to show how this might be achieved from the existing classification of abnormalities. The true pattern of radiological response to a known dust exposure could then be established much sooner than is practicable by existing methods, with perhaps no more than two radiological surveys. Then it should be possible to make full use of the unique data now being collected in the National Coal Board's Pneumoconiosis Field Research, the large scale, long-term study of pneumoconiosis in British coal-mines (Fay and Rae, 1959; Ashford, 1960; Fay and Ashford, 1961).

The prevalence of pneumoconiosis among men working in coal-mines or living in geographicallydefined mining communities has been frequently measured (Fletcher, 1955b; Cochrane, Davies, Chapman, Rae, Rinsler, and Williams, 1956) and the factors affecting the attack rate and progression of complicated pneumoconiosis have been studied (Cochrane, Miall, Clarke, Jarman, Jonathan, and Moore, 1956; Cochrane, Carpenter, Clarke, Jonathan, and Moore, 1956; Cochrane, Moore, and Thomas, 1961a, b). On the other hand until recently nothing had been published on the progression of simple pneumoconiosis. Attempts have been made (Cochrane, 1951) to deduce from prevalence studies a relation between dust exposure and the production of pneumoconiosis, and a sound method of doing this has been proposed by Roach (1953). Even so the method depends on estimates of all past dust exposure being available and reliable, or, if a forwardlooking experiment is planned, on adequate numbers of new entrants to the dusty occupation, with normal radiographs, being successfully followed for many years while their dust exposure is measured by a careful sampling procedure such as that proposed by Oldham and Roach (1952) and by Ashford (1958). Recently Fay and Ashford (1961) have described

\footnotetext{
*For the origins of the scale and of its boundaries see Fletcher and Oldham $(1949,1951)$
}

their own approach to the problems with which this paper is concerned, and this will be discussed later.

The theoretical ideas presented in this paper are based mainly on earlier material collected by the Pneumoconiosis Research Unit in two surveys, two and a half years apart, of the coal-face workers in eight mines; some of the results from a recent third survey are also used. It is unfortunate that there are no suitable records of dust exposure of the men who were radiographed but this study will be primarily concerned with the response to dust exposure.

Classification of Simple Pneumoconiosis.-In this paper simple pneumoconiosis is classified into four categories $0,1,2$, and 3 , defined by standard films. These typify the lowest level of radiological abnormality to be called category 2 or category 3 , and the average appearance of the range of abnormality covered by category 1 . The distinction between category 0 and category 1 is made by a description in words of the smallest amount of specific change that is to be compatible with a reading of category 1 . The whole concept is of a continuum of increasing profusion of specific opacities in the chest radiograph, with certain landmarks, the standard films, placed at intervals along its length. There is no reason to suppose that the category boundaries represent equal intervals of abnormality, measured in any particular manner. They were originally derived by Fletcher and Oldham (1951) by reference to films which, in an earlier study (Fletcher and Oldham, 1949), were placed equally often in pairs of adjacent categories by 10 experienced observers. The categories used in this study were defined by reference to the "definiteness" or otherwise of the pneumoconiosis, by whether it was of degree sufficient for compensation to be payable, and by a distinction between "reticulation" and "nodulation" or "coalescent shadows" in the sense of Hart and Aslett (1942). It is not to be supposed that the boundary between category 0 and category 1 represents the boundary between normal and pneumoconiosis; it has been found (Fletcher, 1955a) that the films of some miners in category 0 can be reliably distinguished from films of men who have never been exposed to industrial dust, while there is no real sense in which the early radiological changes of pneumoconiosis can be said to constitute a disease. The classification is primarily a way of ranking in order the radiographic changes associated with dust exposure, and apparently predisposing to the disease of progressive massive fibrosis.

The four categories $0,1,2$, and 3 were originally defined verbally by Fletcher, Mann, Davies, 
Cochrane, Gilson, and Hugh-Jones (1949) who also suggested the use of standard films exemplifying the boundaries between categories for side-by-side comparison with a film to be classified. Sets of such standard films were issued by the Pneumoconiosis Research Unit. In 1950 the International Labour Organisation (1953) adopted this classification, slightly modified, and later still the standard film issued for category 1 became one typifying the average appearance of this category instead of its lower limit. In 1958 the I.L.O. agreed a new classification (International Labour Organisation, 1959) differing little from the old one, but proposing that the new standard films to be issued by them for each category should be of "typical", i.e. average appearance. When this classification comes into general use it will, therefore, no longer be possible to use the standard films in the same way to determine the category into which a borderline film should be placed.

Problem of Measuring Progression.-In order to emphasize the continuous nature of the process being graded by the $x$-ray categories it is convenient to introduce a scale of $x$ (for $x$-ray change) stretching from zero (absolute normality) to infinity (infinite abnormality). On this scale (Fig. 1) the standard films of the 1953 I.L.O. classification mark arbitrary points, and the ranges between them represent the categories. Any coal-worker's film will show abnor-

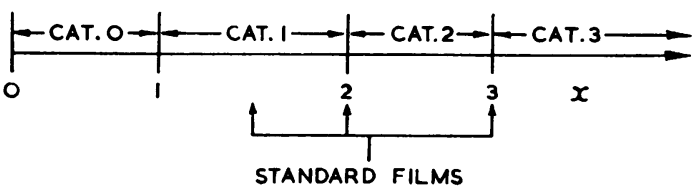

FIG. 1.-The continuum of simple pneumoconiosis with the categories and standard films shown on the arbitrary scale of $x$.

mality of a true amount $x$ which, by reference to the amounts of abnormality shown by the standard films, determines in which category he should be placed. It is convenient further to give numerical values to the arbitrary points at which the boundaries between categories have been placed by the I.L.O. definitions and standard films. The boundary between categories 0 and 1 will be called 1 , that between categories 1 and 2, 2, and that between categories 2 and 3,3 . Then on this scale the three standard films have abnormality $x$ equal to 1.5 (approximately), 2 (exactly), and 3 (exactly). A film of category 0 has an $x$-value less than 1 , a category 1 film has an $x$-value between 1 and 2, and so on.

A film showing true abnormality $2 \cdot 2$ (say) will be read by a perfect observer as category 2 . So also will be a film of true abnormality 2.9 . The first problem that arises is now clear; if a man has progressed in true abnormality from 2.2 to 2.9 , how can we recognize the fact? Had he progressed from 2.9 to $3 \cdot 1$, the perfect observer reading a perfect film would have recorded his first category as 2 , his second as 3 , and the progression would be revealed by the change of category. Yet in the first case the man has increased in abnormality by almost the whole range of a category, while in the second he has progressed only a distance of 0.2 on the scale. If the observers and films were really perfect this problem would not exist, for then a finer scale could be introduced. As it is, this coarse scale has to be used to estimate small differences between amounts of abnormality.

The second problem arises immediately; although it is natural to assume that the distance from $2 \cdot 2$ to 2.9 is greater than that from 2.9 to $3 \cdot 1$, the assumption is not necessarily justified. The scale of $x$ on which these distances are measured was not constructed to ensure that addition and subtraction of numbers on it is valid. An obvious step forward is to try to define $x$-ray change more precisely and quantitatively, and then to obtain a scale on which equally spaced numbers represent equal amounts of $x$-ray change. Even then this scale is not necessarily an appropriate one on which to measure progression. The practical requirement underlying all attempts to measure progression is that it should become possible to relate it to exposure to dust. It is not necessarily true that equal doses of dust produce equal amounts of $x$-ray change. The amount of change produced in an almost normal lung could differ from that produced in a lung already showing some degree of pneumoconiosis.

There are thus two fundamental problems in measuring the progression of simple pneumoconiosis. It is necessary to find a method that overcomes the very heavy grouping of a continuum of $x$-ray change implicit in the use of a few categories; it is necessary to find suitable scales of $x$-ray abnormality.

\section{$\mathrm{X}$-ray Categories and the Continuum}

(a) Use of Distributions of X-ray Readings by Expert Readers.-Few attempts have been made to obtain a more accurate location of an $x$-ray on the continuum than that provided by the four standard categories. Fletcher and Oldham (1949) used the average of the categories recorded by a number of observers, but their purpose was to study and control observer variation rather than to utilize it to obtain a more precise measure of $x$-ray abnormality. Yet evidently such an average is likely to give a measure (on the scale of $x$ defined above) that approaches the true amount of radiological abnormality, $x$. If 10 
experienced observers all read a film as category 2 , it is likely that the true amount of abnormality it shows is that of a typical category 2 , of abnormality about equal to 2.5 on the $x$-scale. If five read it as a category 2 , five as a category 3 , it is reasonable to suppose that it is close to the boundary between categories 2 and 3 , that is, to an $x$-value of 3.0 . In this way observer variation provides a way of locating an $x$-ray more accurately on the continuum than accurate classification into categories can. The process would be more reliable if the $x$-scale were first transformed to a scale on which the amount of observer variation was everywhere equal; but even applied crudely to the $x$-scale itself the resulting averages will indicate the true quantity of abnormality when different observers disagree in their categorization more closely than a whole category number arrived at after discussion between the observers to establish agreement.

With films of good quality it may be possible to gain more information, without in any way changing the standard of $x$-ray classification, by recording doubts expressed by expert readers. They could mention, for example, whenever they feel that a particular film is high, medium, or low in its category, but without trying to define thirds of categories. A film reading experiment on these lines has been organized by F. D. K. Liddell (personal communication) with promising results.

(b) Use of Distributions of X-ray Abnormality Within a Defined Population.-A second method of learning more of the true distribution of abnormality in a batch of films is more subtle. It is applicable only to batches, not to individual films. It depends on the simple and reasonable assumption that any naturally occurring sample of chest radiographs, such as might be obtained from an $x$-ray survey of a defined population, will contain a smooth, continuous distribution of true abnormality. Fig. 2a shows the observed distribution of categories among face workers at a Welsh coal-mine. The assumption is that the true distribution of abnormality is more like that in Fig. 2b than that in Fig. 2c. In Fig. $2 \mathrm{~b}$ the change of frequency along the $x$-ray continuum is smooth and gentle. It is assumed that the number of men with absolutely no dust in their lungs is small; this is reasonable but unimportant in practice. In Fig. $2 c$ there are sudden abrupt changes of frequency; there are no borderline normals, no men in the lower half of category 1 , only typical category 2's and the 3's are equally placed throughout the range of the category.

A distribution such as that in Fig. $2 c$ could no doubt be true; it will be assumed however that the circumstances in which this kind of distribution occurs are rare.

In such a continuous distribution we can specify in simple terms the relative frequency of cases at all points on the continuum; from two surveys each yielding such a distribution we can observe and measure the movement along the axis of each part of the curve or, in other words, the progression at that point of the continuum. (It has been pointed out that there is no reason to expect equal progression at all parts of the continuum even when the dust exposure has been uniform.) A simple way of identifying points on the smooth curve is by means of the proportion of cases lying below particular points. Thus if in one survey $50 \%$ of the area of the fitted smooth curves lies below the $x$-value 0.80 , whereas in a second survey of the same men $50 \%$ of the area lies below 1.03 , we can specify the progression of the 50th percentile as 0.23 . We can similarly specify the progression at any other percentile. Fig. 3 illustrates the procedure for a set
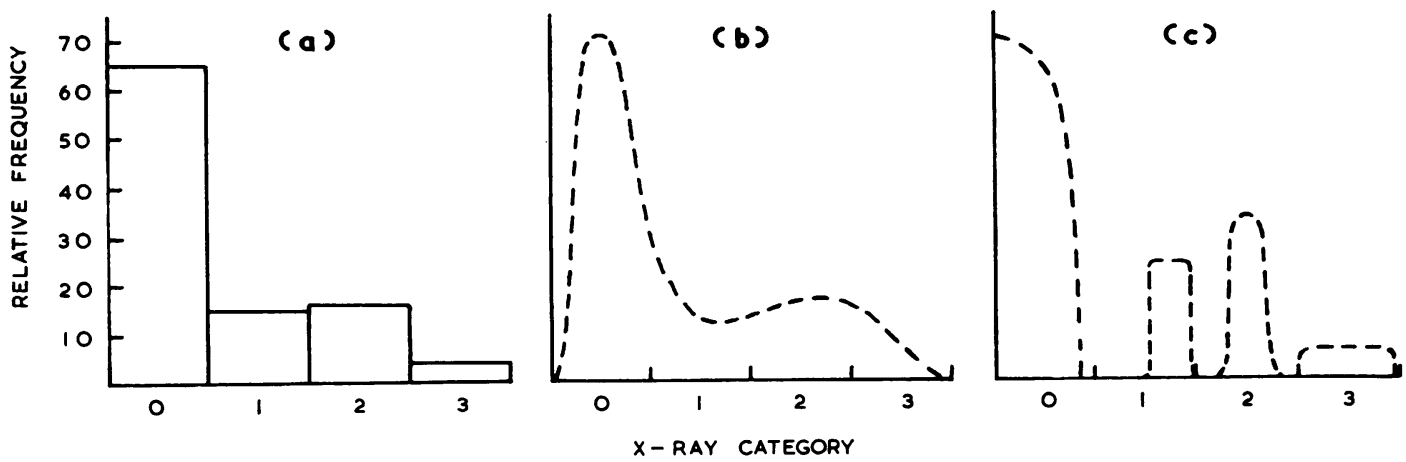

FIG. 2.-Two possible distributions of radiological abnormality, i.e. amount of simple pneumoconiosis (b) and (c), when the observed distribution of discrete categories is the one shown in (a). The boundaries of the $x$-ray categories are the points $0,1,2,3 \ldots$. . of the $x$-scale. 

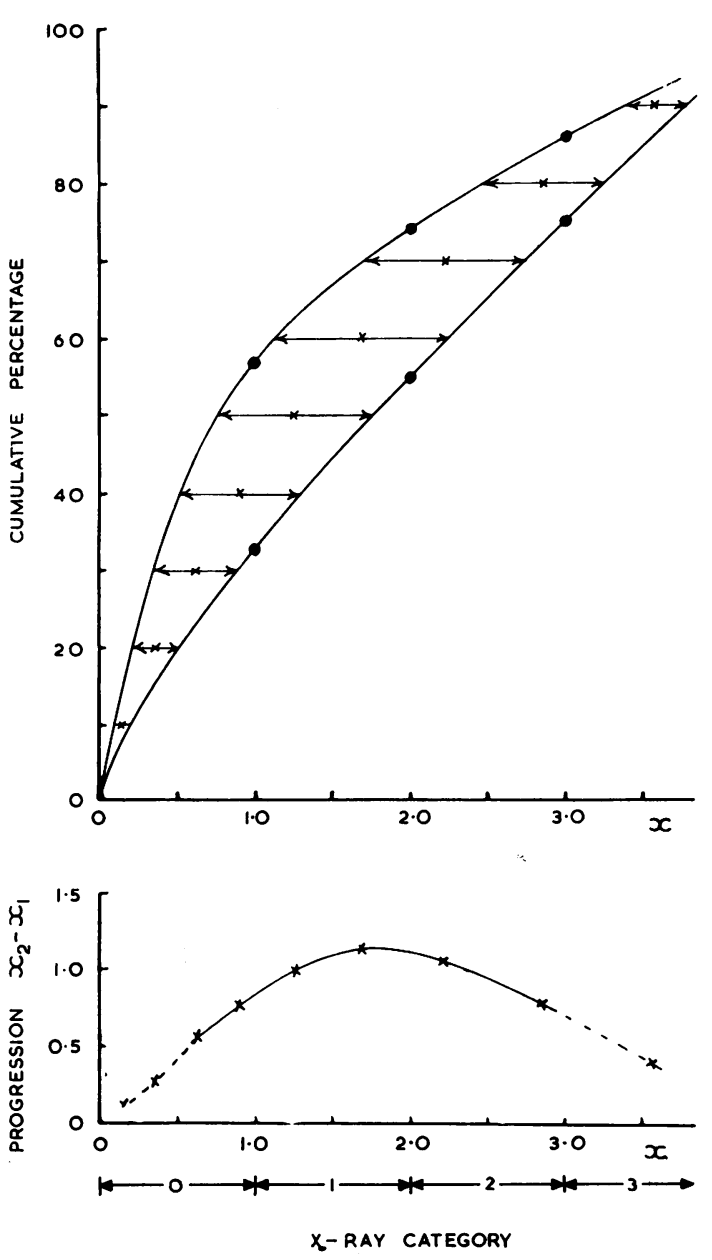

FIG. 3.-The procedure for percentile pairing. The upper part of the figure shows smooth curves drawn through the cumulative distributions found in two surveys of the same men, first survey on the left, second survey on the right. The progression at a number of percentiles (the difference in terms of $x$ between the curves at corresponding heights) is plotted in the lower part of the figure which shows typical variation of progression from point to point on the continuum of abnormality.

of films of 100 men radiographed on two occasions 11 years apart. One reader who classified the films produced the following distributions:

\begin{tabular}{c|c|c} 
Category & 1st Survey & 2nd Survey \\
\hline 0 & 57 & 33 \\
1 & 17 & 22 \\
2 & 12 & 20 \\
3 & 14 & 25
\end{tabular}

The upper part of Fig. 3 shows these distributions plotted cumulatively; the left-hand curve has been drawn to pass smoothly through the first survey points: the origin, $57 \%$ at an $x$-value of 1.0 (normal films), $74 \%$ at $x=2.0$ (normal and category 1 films), and $86 \%$ at $x=3.0$ (normals and categories 1 and 2 ). The right-hand curve has been drawn through the second survey points. The horizontal separation of the curves at $10 \%, 20 \%$ etc. is taken to indicate the progression of these percentiles, and is plotted in the lower part of Fig. 3 at $x$-values midway between those of the first and second survey curves at these percentiles, or, effectively, at $x$-values giving the amount of abnormality half-way between the surveys.*

Let us consider the implications of this device, which we shall call percentile pairing. The progression at any one percentile can correspond exactly to the progression of an individual, provided each man retains his relative position in the distribution of abnormality. This is unlikely to be true exactly, for there are known to be random variations of dust exposures even among men in similar surroundings; also it is suspected that effects of similar exposures vary among individuals. But it is quite likely to be approximately true. For example the 43rd man out of 80 at the first survey might become the 47th of the same 80 men at the second survey, while the 42nd becomes the 41st and the 44th becomes the 40th. This sort of change would generally be accepted as random, and percentile pairing would then be meaningful. Assuming then that the progression of a percentile does correspond to such a localized average of progression of a few individuals, we shall next discuss its variation over the continuum of abnormality.

Two interpretations of this variation can be regarded as extreme. First, if every man in the population had retained the same amount of additional dust in his lungs, variation in amount of progression from one part of the continuum to another must be the result of non-uniformity of the $x$-scale in terms of added dust. A true dust-scale would put the points $1 \cdot 0$ and $2 \cdot 0$, the $0-1$ and $1-2$ boundaries, closer together, so that the high value of $x_{2}-x_{1}$ shown there would be reduced to equality with the lower values elsewhere. A transformation of the $x$-scale which achieves this has been derived empirically from the data to be presented later. Each pair of surveys then leads to a plot of progression against mean abnormality tending to form a horizontal straight line at a height representing the true amount of progression, defined as additional

*This reference point is used rather than either $x_{1}$ or $x_{2}$ for two technical reasons. First, the values (of $\left.x_{2}-x_{1}\right)$ at $x_{1}$ and $x_{9}$ will in
general be correlated (with $x_{1}$ and $x_{9}$ ) and second, because, with general be correlated (with $x_{1}$ and $x_{2}$ ) and second, because, with
smooth curves, the change will more nearly approximate to the true smooth curves, the change will more nearly approxim

gradient at the midpoint than to that at either end.
A similar problem arises in many analyses of follow-up data, e.g. blood pressures of a group of people in 1957 and of the same people in, say, 1961 (see also Oldham, 1962). 
dust-retention, measured in the new scale of $x$-ray change. This scale will be called the $w$-scale and is appropriate on one extreme assumption.

Second, it is possible that the $x$-scale itself is uniform in terms of retained dust, and that indeed some men, in particular those with a mid-survey category of 1 , were progressing faster than others. This is obviously possible, in that self-selection is continuously proceeding in a mining population. Men exposed to much dust would quickly progress to category 1 , where the surveys would find them still progressing fast. Men exposed to little dust would remain in category 0 , with a slow progression rate. Men in categories 2 and 3 would tend to be moved, or to move themselves, to less dusty places where they would progress less fast.

So far no way has been shown for deciding whether the truth lies at one or other extreme or in between; the appropriate scale on which to measure progression may be neither the $x$-scale nor the $w$ scale. We now consider how the appropriate scale may be derived.

A Scale for X-ray Change Corresponding to Dust Retained in Lungs.--Rivers et al. (1960) have analysed the relation between $x$-ray abnormality, lung pathology, and the dust content of the lungs in a series of cases studied post mortem. They established a scale of $x$-ray abnormality, the $X$-scale, on which values of $X$ were linearly related to the amount of coal and other dust in the lungs. The contribution to the $X$-value made by the coal dust was smaller by a factor of 9 than that made by an equal weight of the other, siliceous dust. The type and extent of the pathology was only weakly correlated with the composition of the dust. The period the dust had been retained in the lungs did not appear to affect the $x$-ray abnormality directly. They concluded therefore that the effect of the dust was a purely physical one, determined by the absorption and scatter of $X$-radiation by particles of different molecular weights.

The $X$-scale derived empirically from this study has precisely the properties that we have already seen are necessary for a proper measurement of progression of simple pneumoconiosis in life. Irrespective of the amount of $x$-ray abnormality already seen in the lungs, a specific amount of dust of the same composition additionally retained induces the same amount of progression in the chest radiograph when this is measured on the $X$-scale. Equal doses of dusts of different composition will in general produce different amounts of progression, but this implies only that in relating progression in life to dust exposure an appropriate measure of response is as necessary as an appropriate measure of exposure. In silicosis, for example, one would expect the time during which dust was retained in the lungs to be an essential ingredient in the measure of both dose and response. In coal-workers' simple pneumoconiosis it still appears reasonable to ignore the duration of dust retention. Any measurement of the radiological progression of silicosis would be expected to correlate best with a measurement of dose which allowed for the duration of dust retention; equally it may appear that both dose and radiological response in coal-workers' pneumoconiosis will need to be correlated on scales that allow for the disproportionate effect of siliceous dust compared with that of coal dust.

\section{Part II: Application}

Material.-The theory of a method of measuring the radiological progression of coal-workers' pneumoconiosis has now been sketched out. Its application to actual data will be illustrated by using the studies of eight coal-mines made by Professor A. L. Cochrane and his survey team between 1949 and 1955.

Each mine was visited on two occasions, separated by two and a half years, and on each occasion $98 \%$ or more of the working population was radiographed. The films to be discussed are those of the 689 men in these coal-mines who had worked only on the coal-face during the interval. The films of these men were read for pneumoconiosis in two ways. In the first the 689 pairs of films were separated and the individual films were presented to the readers in a random order. There was no indication by which the readers could detect whether a film was the first or second of an individual man, while the number involved was so great that remembering the reading of an individual's film when its pair was presented was virtually impossible. In the second, the two films of each man were presented simultaneously to the readers; they were not told which was which. In both cases the same two readers worked together, discussing each film or pair of films, and finally determining for each film an agreed $x$-ray category. The films were read separately a third time by two other readers who classified their radiographic quality as "acceptable", "black", "grey", or "white". The reasons for adopting this classification are given in another paper (Wise and Oldham, 1963).

The full results of the readings for simple pneumoconiosis are given in Table 1. The first and second columns specify the readings of the first survey and second survey films according to the separate and side-by-side methods of reading respectively. The remaining columns give the number of subjects in 
TABLE 1

THE FOUR READINGS OF RADIOLOGICAL CATEGORY OF EACH COAL-FACE WORKER IN THE 1st AND 2nd SURVEYS OF EIGHT PITS

\begin{tabular}{|c|c|c|c|c|c|c|c|c|c|c|c|}
\hline \multicolumn{2}{|c|}{ Films Separate } & \multicolumn{2}{|c|}{ Films Together } & \multicolumn{8}{|c|}{ Pit } \\
\hline $1 \mathrm{st}$ & 2nd & 1st & 2nd & $\mathbf{A}$ & B & $\mathrm{C}$ & D & $E$ & $F$ & $\mathbf{G}$ & H \\
\hline 0 & 0 & $\begin{array}{l}0 \\
0 \\
1\end{array}$ & $\begin{array}{l}0 \\
1 \\
1\end{array}$ & $\begin{array}{r}41 \\
4 \\
2\end{array}$ & $\begin{array}{r}18 \\
1 \\
2\end{array}$ & $\begin{array}{r}45 \\
1 \\
-\end{array}$ & $\begin{array}{r}31 \\
2 \\
-\end{array}$ & $\begin{array}{r}4 ! \\
2 \\
1\end{array}$ & $\begin{array}{r}53 \\
2 \\
3\end{array}$ & $\begin{array}{r}40 \\
3 \\
-\end{array}$ & $\begin{array}{r}30 \\
2 \\
4\end{array}$ \\
\hline 0 & 1 & $\begin{array}{l}0 \\
0 \\
1\end{array}$ & $\begin{array}{l}0 \\
1 \\
1\end{array}$ & $\begin{array}{l}2 \\
2 \\
3\end{array}$ & $\overline{1}$ & $\begin{array}{l}9 \\
3 \\
1\end{array}$ & $\begin{array}{l}8 \\
7 \\
2\end{array}$ & $\begin{array}{l}5 \\
2 \\
-\end{array}$ & $\begin{array}{r}12 \\
7 \\
4\end{array}$ & $\begin{array}{l}1 \\
5 \\
2\end{array}$ & $\begin{array}{l}2 \\
4 \\
3\end{array}$ \\
\hline 0 & 2 & $\begin{array}{l}0 \\
0 \\
0 \\
1 \\
1 \\
1 \\
2\end{array}$ & $\begin{array}{l}0 \\
1 \\
2 \\
1 \\
2 \\
3 \\
2\end{array}$ & $\begin{array}{l}\overline{1} \\
\bar{y} \\
\bar{y} \\
\overline{-}\end{array}$ & $\begin{array}{l}\bar{y} \\
\bar{y} \\
\bar{y} \\
\bar{y}\end{array}$ & $\begin{array}{l}\overline{7} \\
1 \\
\bar{y} \\
\bar{y} \\
\bar{y}\end{array}$ & $\begin{array}{l}\overline{1} \\
\frac{1}{1} \\
\frac{2}{2}\end{array}$ & $\begin{array}{l}\overline{3} \\
\overline{3} \\
\overline{1}\end{array}$ & $\begin{array}{l}5 \\
7 \\
5 \\
5 \\
1\end{array}$ & $\begin{array}{l}\overline{1} \\
\overline{1} \\
\overline{1}\end{array}$ & $\begin{array}{l}\frac{1}{1} \\
\frac{1}{1} \\
-\end{array}$ \\
\hline 1 & 1 & $\begin{array}{l}\mathbf{0} \\
0 \\
1 \\
2\end{array}$ & $\begin{array}{l}0 \\
1 \\
1 \\
2\end{array}$ & $\begin{array}{l}\overline{2} \\
4 \\
-\end{array}$ & $\begin{array}{l}\overline{1} \\
1 \\
2\end{array}$ & $\begin{array}{l}1 \\
1 \\
2 \\
-\end{array}$ & $\frac{1}{2}$ & $\begin{array}{l}\overline{-} \\
\overline{3}\end{array}$ & $\begin{array}{l}\overline{2} \\
6 \\
-\end{array}$ & $\bar{z}$ & $\frac{1}{1}$ \\
\hline 1 & 2 & $\begin{array}{l}0 \\
1 \\
1 \\
2\end{array}$ & $\begin{array}{l}1 \\
1 \\
2 \\
2\end{array}$ & $\begin{array}{l}\overline{2} \\
4 \\
1\end{array}$ & $\begin{array}{l}\bar{z} \\
\bar{z}\end{array}$ & $\frac{\overline{2}}{\overline{1}}$ & $\begin{array}{l}\overline{4} \\
2 \\
-\end{array}$ & $\begin{array}{l}2 \\
2 \\
2 \\
-\end{array}$ & $\begin{array}{l}3 \\
3 \\
2\end{array}$ & $\frac{\overline{2}}{3}$ & $\begin{array}{l}\overline{2} \\
\overline{1}\end{array}$ \\
\hline 1 & 3 & $\begin{array}{l}0 \\
1 \\
2 \\
2\end{array}$ & $\begin{array}{l}2 \\
2 \\
2 \\
3\end{array}$ & $\begin{array}{l}\bar{z} \\
\bar{z}\end{array}$ & $\begin{array}{l}\bar{z} \\
\bar{z}\end{array}$ & $\begin{array}{l}\bar{z} \\
\bar{z}\end{array}$ & $\frac{1}{1}$ & $\begin{array}{l}\bar{z} \\
\bar{z}\end{array}$ & $\overline{\frac{2}{3}}$ & $\begin{array}{l}\overline{1} \\
2 \\
-\end{array}$ & $\bar{z}$ \\
\hline 2 & 2 & $\begin{array}{l}0 \\
1 \\
1 \\
2 \\
2 \\
3\end{array}$ & $\begin{array}{l}1 \\
1 \\
2 \\
2 \\
3 \\
3\end{array}$ & $\begin{array}{c}\bar{y} \\
\overline{1} \\
\overline{11} \\
\overline{-}\end{array}$ & $\begin{array}{l}\overline{-} \\
\overline{2} \\
\overline{-}\end{array}$ & $\begin{array}{l}1 \\
\frac{1}{2} \\
- \\
-\end{array}$ & $\begin{array}{l}\overline{1} \\
\overline{4} \\
\overline{-}\end{array}$ & $\begin{array}{l}\overline{1} \\
\overline{3} \\
1 \\
1\end{array}$ & $\begin{array}{l}\overline{1} \\
\overline{5} \\
\overline{-}\end{array}$ & $\begin{array}{l}\overline{-} \\
\overline{6} \\
1 \\
-\end{array}$ & $\begin{array}{l}- \\
\frac{1}{5} \\
\frac{5}{1}\end{array}$ \\
\hline 2 & 3 & $\begin{array}{l}1 \\
1 \\
1 \\
2 \\
2 \\
3\end{array}$ & $\begin{array}{l}1 \\
2 \\
3 \\
2 \\
3 \\
3\end{array}$ & $\begin{array}{l}\bar{z} \\
\overline{2} \\
\bar{z}\end{array}$ & $\begin{array}{l}\bar{z} \\
\overline{1} \\
\overline{-}\end{array}$ & $\begin{array}{l}\bar{z} \\
\bar{z} \\
\overline{1}\end{array}$ & $\begin{array}{l}\frac{1}{1} \\
\overline{2} \\
1 \\
3\end{array}$ & $\begin{array}{l}- \\
\bar{z} \\
\overline{2}\end{array}$ & $\begin{array}{l}\overline{3} \\
\overline{3} \\
1 \\
3\end{array}$ & $\frac{-}{1}$ & $\begin{array}{l}\overline{2} \\
\overline{1} \\
1\end{array}$ \\
\hline 3 & 3 & $\begin{array}{l}2 \\
2 \\
3\end{array}$ & $\begin{array}{l}2 \\
3 \\
3 \\
\end{array}$ & $\overline{4}$ & $\overline{3}$ & $\frac{1}{6}$ & $\overline{4}$ & $\overline{5}$ & $\begin{array}{r}\overline{2} \\
10\end{array}$ & $\begin{array}{l}\overline{1} \\
4\end{array}$ & $\begin{array}{r}2 \\
11 \\
11\end{array}$ \\
\hline 1 & 0 & $\begin{array}{l}0 \\
0 \\
1\end{array}$ & $\begin{array}{l}0 \\
1 \\
1\end{array}$ & $\frac{1}{1}$ & $\bar{y}$ & $\frac{1}{2}$ & $\overline{\bar{i}}$ & $\bar{z}$ & $\begin{array}{l}\bar{y} \\
\bar{y}\end{array}$ & $\overline{1}$ & $\overline{-}$ \\
\hline 2 & 0 & $\frac{1}{2}$ & $\frac{1}{2}$ & 1 & $\overline{-}$ & $\overline{-}$ & - & $\overline{-}$ & $\overline{-}$ & $\bar{i}$ & $\bar{z}$ \\
\hline 2 & 1 & $\begin{array}{l}1 \\
2\end{array}$ & $\begin{array}{l}1 \\
2\end{array}$ & i & $\overline{-}$ & $\overline{-}$ & - & $\overline{-}$ & $\frac{1}{-}$ & $\overline{-}$ & 2 \\
\hline 3 & 1 & 2 & 2 & - & - & 1 & - & - & - & - & - \\
\hline 3 & 2 & $\frac{2}{3}$ & 3 & $\overline{-}$ & 1 & - & $\overline{-}$ & $\overline{-}$ & $\overline{1}$ & 1 & $\begin{array}{l}1 \\
1\end{array}$ \\
\hline All rea & & & & 90 & 33 & 87 & 83 & 82 & 148 & 82 & 84 \\
\hline
\end{tabular}

each separate pit so classified. When the films were read separately the second survey film was occasionally given a lower category than the first. These cases appear below the line in Table 1. This never occurred when the films were read side by side, and it may be that these readings are solely due to the effect of observer error. It is encouraging that they represent less than $3 \%$ of the total number of pairs.

Much of the analysis now to be presented had one particular aim, namely, to compare the pits with each other in relation to the amount of progression in them. By almost any criterion the progression in pit B is the least and the next lowest is A. It is not at all obvious how to compare the remaining six.

Method of Reading.- The first thing to consider is what light is thrown on the relative merits of the 
two modes of reading. Most radiologists would expect that the comparative side-by-side method would be more reliable, in that the readers would find it easier to notice and allow for peculiarities of individual subjects. Against this must be set the possibility that bias might be introduced by the appearance of one film influencing the reader in his categorization of the other. In fact it was found that a large bias of this sort was present.

Table 2 shows, for each pit, the distribution of changes of category (category of second survey film minus category of first survey film) by the two methods of reading. There was an obvious and consistent tendency to read fewer changes of category, and less extreme ones, when the films were read together. This is shown also by the mean changes of category, which, except in pits A and B, were always larger when the films were read separately (even though the occasional "regressions" tend to diminish the mean change). On the other hand when the first and second survey categories were averaged (giving a between-survey category) the

TABLE 2

DISTRIBUTION OF CHANGES OF CATEGORY (2nd SURVEY FILM MINUS 1st SURVEY FILM) IN EACH PIT ACCORDING TO THE TWO WAYS OF READING

\begin{tabular}{|c|c|c|c|c|c|c|c|}
\hline \multirow{2}{*}{ Pit } & \multirow{2}{*}{ Reading } & \multicolumn{5}{|c|}{ Change of Category } & \multirow{2}{*}{$\begin{array}{c}\text { Mean Change } \\
(\times 10)\end{array}$} \\
\hline & & -2 & -1 & 0 & +1 & +2 & \\
\hline $\mathbf{A}$ & $\begin{array}{l}\text { (i)* } \\
\text { (ii) } \dagger\end{array}$ & $\overline{2}$ & $\overline{3}$ & $\begin{array}{l}77 \\
68\end{array}$ & $\begin{array}{l}13 \\
16\end{array}$ & $\overline{1}$ & $\begin{array}{l}1.44 \\
1.22\end{array}$ \\
\hline B & $\begin{array}{l}\text { (i) } \\
\text { (ii) }\end{array}$ & - & $\overline{1}$ & $\begin{array}{l}30 \\
30\end{array}$ & $\begin{array}{l}3 \\
2\end{array}$ & $\overline{-}$ & $\begin{array}{l}0.91 \\
0.30\end{array}$ \\
\hline C & (i) & $\overline{1}$ & $\overline{1}$ & $\begin{array}{l}72 \\
60\end{array}$ & $\begin{array}{l}14 \\
17\end{array}$ & $\begin{array}{l}1 \\
8\end{array}$ & $\begin{array}{l}1 \cdot 84 \\
3 \cdot 45\end{array}$ \\
\hline D & $\begin{array}{l}\text { (i) } \\
\text { (ii) }\end{array}$ & - & $\overline{1}$ & $\begin{array}{l}67 \\
45\end{array}$ & $\begin{array}{l}15 \\
30\end{array}$ & $\begin{array}{l}1 \\
7\end{array}$ & $\begin{array}{l}2.05 \\
5 \cdot 18\end{array}$ \\
\hline $\mathrm{E}$ & $\begin{array}{l}\text { (i) } \\
\text { (ii) }\end{array}$ & - & - & $\begin{array}{l}65 \\
60\end{array}$ & $\begin{array}{l}17 \\
15\end{array}$ & $\overline{7}$ & $\begin{array}{l}2.07 \\
3.54\end{array}$ \\
\hline $\mathbf{F}$ & $\begin{array}{l}\text { (i) } \\
\text { (ii) }\end{array}$ & - & $\overline{2}$ & $\begin{array}{r}114 \\
84\end{array}$ & $\begin{array}{l}33 \\
41\end{array}$ & 21 & $\begin{array}{l}2 \cdot 36 \\
5 \cdot 47\end{array}$ \\
\hline G & $\begin{array}{l}\text { (i) } \\
\text { (ii) }\end{array}$ & $\bar{l}$ & $\overline{3}$ & $\begin{array}{l}66 \\
57\end{array}$ & $\begin{array}{l}14 \\
15\end{array}$ & $\frac{2}{6}$ & $\begin{array}{l}2 \cdot 20 \\
2 \cdot 80\end{array}$ \\
\hline $\mathbf{H}$ & $\begin{array}{l}\text { (i) } \\
\text { (ii) }\end{array}$ & - & $\overline{4}$ & $\begin{array}{l}71 \\
60\end{array}$ & $\begin{array}{l}13 \\
17\end{array}$ & $\overline{3}$ & $\begin{array}{l}1.55 \\
2.26\end{array}$ \\
\hline
\end{tabular}

*Together +Separate

TABLE 3

ESTIMATES OF PREVALENCE DISTRIBUTIONS HALFWAY BETWEEN THE TWO SURVEYS IN EACH PIT, OBTAINED FROM (i) SIDE-BY-SIDE AND (ii) SEPARATE READINGS OF THE FILMS

\begin{tabular}{|c|c|c|c|c|c|c|c|c|c|}
\hline \multirow{2}{*}{ Pit } & \multirow{2}{*}{ Reading } & \multicolumn{7}{|c|}{ Mean Category of 1st and 2nd Surveys } & \multirow{2}{*}{$\begin{array}{c}\text { Mean of } \\
\text { Distribution }\end{array}$} \\
\hline & & 0 & $\frac{1}{2}$ & 1 & 11 & 2 & $2 \frac{1}{2}$ & 3 & \\
\hline A & $\begin{array}{l}\text { (i) } \\
\text { (ii) }\end{array}$ & $\begin{array}{l}44 \\
47\end{array}$ & $\begin{array}{l}9 \\
9\end{array}$ & $\begin{array}{r}13 \\
9\end{array}$ & $\begin{array}{l}4 \\
8\end{array}$ & $\begin{array}{l}16 \\
11\end{array}$ & $\overline{2}$ & $\begin{array}{l}4 \\
4\end{array}$ & $\begin{array}{l}0.750 \\
0.717\end{array}$ \\
\hline B & $\begin{array}{l}\text { (i) } \\
\text { (ii) }\end{array}$ & $\begin{array}{l}18 \\
21\end{array}$ & $\begin{array}{l}3 \\
1\end{array}$ & $\begin{array}{l}3 \\
4\end{array}$ & - & $\begin{array}{l}6 \\
2\end{array}$ & $\overline{2}$ & $\begin{array}{l}3 \\
3\end{array}$ & $\begin{array}{l}0.773 \\
0.682\end{array}$ \\
\hline C & (i) & $\begin{array}{l}56 \\
46\end{array}$ & $\begin{array}{l}13 \\
14\end{array}$ & $\begin{array}{r}6 \\
12\end{array}$ & $\overline{3}$ & $\begin{array}{l}5 \\
4\end{array}$ & 1 & $\begin{array}{l}6 \\
7\end{array}$ & $\begin{array}{l}0.494 \\
0.632\end{array}$ \\
\hline D & (i) & $\begin{array}{l}41 \\
33\end{array}$ & $\begin{array}{l}10 \\
18\end{array}$ & $\begin{array}{r}13 \\
8\end{array}$ & $\begin{array}{l}4 \\
6\end{array}$ & $\begin{array}{l}7 \\
7\end{array}$ & $\begin{array}{l}1 \\
7\end{array}$ & $\begin{array}{l}7 \\
4\end{array}$ & $\begin{array}{l}0.741 \\
0.837\end{array}$ \\
\hline $\mathbf{E}$ & (i) & $\begin{array}{l}46 \\
44\end{array}$ & $\begin{array}{l}9 \\
7\end{array}$ & $\begin{array}{r}7 \\
12\end{array}$ & $\begin{array}{l}5 \\
6\end{array}$ & $\begin{array}{l}6 \\
6\end{array}$ & $\begin{array}{l}3 \\
2\end{array}$ & $\begin{array}{l}6 \\
5\end{array}$ & $\begin{array}{l}0.689 \\
0.689\end{array}$ \\
\hline $\mathbf{F}$ & (i) & $\begin{array}{l}65 \\
58\end{array}$ & $\begin{array}{l}16 \\
23\end{array}$ & $\begin{array}{l}22 \\
25\end{array}$ & $\begin{array}{r}11 \\
8\end{array}$ & $\begin{array}{l}14 \\
11\end{array}$ & $\begin{array}{r}6 \\
10\end{array}$ & $\begin{array}{l}14 \\
13\end{array}$ & $\begin{array}{l}0.889 \\
0.909\end{array}$ \\
\hline G & (i) & $\begin{array}{l}41 \\
43\end{array}$ & $\begin{array}{l}10 \\
10\end{array}$ & $\begin{array}{l}6 \\
6\end{array}$ & $\frac{2}{5}$ & $\begin{array}{l}16 \\
10\end{array}$ & $\begin{array}{l}3 \\
3\end{array}$ & $\begin{array}{l}4 \\
5\end{array}$ & $\begin{array}{l}0.799 \\
0.744\end{array}$ \\
\hline $\mathbf{H}$ & (i) & $\begin{array}{l}34 \\
36\end{array}$ & $\begin{array}{l}6 \\
9\end{array}$ & $\begin{array}{r}13 \\
6\end{array}$ & $\frac{5}{5}$ & $\begin{array}{r}10 \\
7\end{array}$ & $\frac{2}{7}$ & $\begin{array}{l}14 \\
14\end{array}$ & $\begin{array}{l}1.077 \\
1.089\end{array}$ \\
\hline
\end{tabular}


results were much the same whichever method of reading was used. Table 3 shows the distributions of these average categories in the eight pits. For each pit the distributions obtained by the two methods of reading are closely similar, except that in the side-byside method the frequency of whole number means is greater than that of halves. This reflects the smaller number of changes of category by this method of reading. Otherwise the (small) differences show no regular pattern except that the mean category for the separate readings of $\mathrm{C}$ is decidedly larger, and significantly so, than that for the paired readings. That for $\mathrm{D}$ is also significantly larger if considered on its own, but may not be so as the largest of seven pairs of differences. The other six differences could certainly form part of a random distribution with mean zero. There is an interesting reason why $\mathrm{C}$ is different from all the others which will become clear later.

The results as a whole strongly suggest that the side-by-side readings must be biased, in such a way that the first film is more often given too high a category than one too low, and the second film more often one too low than one too high. Alternatively, the readers, when reading the films separately in random order, could generally recognize a film from whatever batch it came as belonging to a first or second survey and showed a downward or upward bias in their reading of it. This seems highly unlikely, and there is little doubt that the first interpretation is the correct one. It is still possible that there is more random error when films are read separately, and that more films are indeed classified correctly when read side by side. But the fact that the errors in the side-by-side readings tend to be in the inward direction and cause a bias in estimating progression shows that they must for the present be discarded.

Effect of Radiographic Technique.-In relation to radiological progression the effects of technique seemed at first to be very considerable and difficult to allow for. The method adopted will only be outlined here, and fuller details are given in another paper (Wise and Oldham, 1963).

The first difficulty was that the proportions of progressions appeared to depend very much upon the technique of the two films concerned, but in no simple way. About $20 \%$ of the subjects showed a change of category when the first survey film was acceptable, about 40 to $50 \%$ when it was black or grey, and 10 to $20 \%$ when it was white. There was no very clear dependence of the percentage on the quality of the second film. The second difficulty was that the numbers of good, white, grey, and black films varied greatly between the first and second surveys in each pit and also from pit to pit. However it was possible to compare distributions of the categories of pneumoconiosis of acceptable films with at least one kind of imperfect film within the same pit and for the same survey. This comparison showed that in general the distribution of readings on any kind of poor film was less widely spread than the distribution of good films.

The numbers of films in each group are too small for the full effects of imperfect technique to be specified precisely. It is, as much as anything, the difficulty in assessing its effects precisely, and then in allowing for it, that makes it difficult to specify the amount of progression that has occurred in the present series. There are too many imperfect films for these to be simply omitted. Despite this, we can make approximate corrections since we are estimating the progression and its variation for the whole group. A smooth distribution function was fitted to each sub-group within a pit where the numbers were sufficient (see Appendix $A$ for the type of function used). The spread of the distributions was measured by their standard deviations; when, as was usually the case, the standard deviation in a sub-group with a particular kind of poor film was smaller than the corresponding one for good films it was multiplied by a constant factor; three different factors were used for the black, grey, and white sub-groups, obtained from a weighted average of observed ratios for different pits and surveys. This correction was not applicable to pit $\mathrm{A}$, where the observed standard deviations of unacceptable films were not smaller. Pit A was omitted from most of the further analyses for this reason. After this correction we are left with two or three smooth curves for the two surveys in each pit. These can be superposed. This yields the pairs of smoothed distributions, specified by their percentiles in Table 4. The main part of the analysis now consists in estimating and interpreting the change of each first curve into the corresponding second one.

\section{Measures of Progression}

1. On the X-ray Scale, the $x$-scale.-As described earlier, a smoothed distribution of progression is now obtained by comparing corresponding percentiles of the distribution given in Table 4. In Fig. 4, for each pit values of $x_{2}-x_{1}$ for the nine percentiles 10 to 90 have been plotted against the mean values $\frac{1}{2}\left(x_{1}+x_{2}\right)$, and the points joined by a smooth curve. Pit B has been omitted from this figure since, as can be seen from Table 2, the amount of progression there was negligible.

The curves for the remaining six pits are of similar but not identical shape. They vary most in category 3 , where the data were few and where 
TABLE 4

PERCENTILES OF SMOOTHED DISTRIBUTIONS, CORRECTED FOR TECHNIQUE, ON ORDINARY $x$-SCALE $\left(x_{1}, 1\right.$ st SURVEY, $x_{2}, 2$ nd SURVEY): PITS A AND B OMITTED (SEE TEXT)

\begin{tabular}{|c|c|c|c|c|c|c|c|c|c|c|c|}
\hline & \multirow{2}{*}{ Pit } & \multicolumn{9}{|c|}{ Percentile } & \multirow{2}{*}{$\begin{array}{c}\text { Mean of } \\
x_{2}-x_{1}\end{array}$} \\
\hline & & 10 & 20 & 30 & 40 & 50 & 60 & 70 & 80 & 90 & \\
\hline $\mathrm{C}$ & $\begin{array}{l}x_{1} \\
x_{2} \\
x_{2}-x_{1}\end{array}$ & $\begin{array}{l}0.17 \\
0.32 \\
0.15\end{array}$ & $\begin{array}{l}0.19 \\
0.39 \\
0.20\end{array}$ & $\begin{array}{l}0.22 \\
0.43 \\
0.21\end{array}$ & $\begin{array}{l}0.24 \\
0.61 \\
0.37\end{array}$ & $\begin{array}{l}0.28 \\
0.92 \\
0.64\end{array}$ & $\begin{array}{l}0.35 \\
1.47 \\
1.12\end{array}$ & $\begin{array}{l}0.50 \\
2.01 \\
1.51\end{array}$ & $\begin{array}{l}1.47 \\
2.56 \\
1.09\end{array}$ & $\begin{array}{l}3.10 \\
3.16 \\
0.06\end{array}$ & 0.535 \\
\hline D & $\begin{array}{l}x_{1} \\
x_{2} \\
x_{2}-x_{1}\end{array}$ & $\begin{array}{l}0.29 \\
0.34 \\
0.05\end{array}$ & $\begin{array}{l}0.35 \\
043 \\
0.08\end{array}$ & $\begin{array}{l}0.42 \\
0.58 \\
0.16\end{array}$ & $\begin{array}{l}0.53 \\
0.80 \\
0.27\end{array}$ & $\begin{array}{l}0.79 \\
1.45 \\
0.66\end{array}$ & $\begin{array}{l}1 \cdot 30 \\
2 \cdot 00 \\
0 \cdot 70\end{array}$ & $\begin{array}{l}1.95 \\
2.51 \\
0.56\end{array}$ & $\begin{array}{l}2.57 \\
2.99 \\
0.42\end{array}$ & $\begin{array}{l}3 \cdot 22 \\
3 \cdot 55 \\
0 \cdot 33\end{array}$ & 0.323 \\
\hline E & $\begin{array}{l}x_{1} \\
x_{2} \\
x_{2}-x_{1}\end{array}$ & $\begin{array}{l}0.24 \\
0.33 \\
0.09\end{array}$ & $\begin{array}{l}0 \cdot 28 \\
0 \cdot 38 \\
0 \cdot 10\end{array}$ & $\begin{array}{l}0.32 \\
0.47 \\
0.15\end{array}$ & $\begin{array}{l}0.37 \\
0.62 \\
0.25\end{array}$ & $\begin{array}{l}0.44 \\
0.90 \\
0.46\end{array}$ & $\begin{array}{l}0.59 \\
1.42 \\
0.83\end{array}$ & $\begin{array}{l}1.03 \\
1.98 \\
0.95\end{array}$ & $\begin{array}{l}1.88 \\
2.57 \\
0.69\end{array}$ & $\begin{array}{l}2 \cdot 81 \\
3 \cdot 16 \\
0 \cdot 35\end{array}$ & 0.387 \\
\hline $\mathbf{F}$ & $\begin{array}{l}x_{1} \\
x_{2} \\
x_{2}-x_{1}\end{array}$ & $\begin{array}{l}0.23 \\
0 \cdot 33 \\
0 \cdot 10\end{array}$ & $\begin{array}{l}0.27 \\
0.43 \\
0.16\end{array}$ & $\begin{array}{l}0.32 \\
0.58 \\
0.26\end{array}$ & $\begin{array}{l}0.38 \\
0.91 \\
0.53\end{array}$ & $\begin{array}{l}0.49 \\
1.50 \\
1.01\end{array}$ & $\begin{array}{l}0.79 \\
2.06 \\
1.27\end{array}$ & $\begin{array}{l}1.65 \\
2.57 \\
0.92\end{array}$ & $\begin{array}{l}2.53 \\
3.03 \\
0.50\end{array}$ & $\begin{array}{l}3.42 \\
3.62 \\
0.20\end{array}$ & 0.495 \\
\hline $\mathbf{G}$ & $\begin{array}{l}x_{1} \\
x_{2} \\
x_{2}-x_{1}\end{array}$ & $\begin{array}{l}0.22 \\
0.26 \\
0.04\end{array}$ & $\begin{array}{l}0.26 \\
0.31 \\
0.05\end{array}$ & $\begin{array}{l}0 \cdot 30 \\
0 \cdot 38 \\
0 \cdot 08\end{array}$ & $\begin{array}{l}0.36 \\
0.46 \\
0.10\end{array}$ & $\begin{array}{l}0.45 \\
0.65 \\
0.20\end{array}$ & $\begin{array}{l}0.73 \\
1.17 \\
0.44\end{array}$ & $\begin{array}{l}1.58 \\
2.05 \\
0.47\end{array}$ & $\begin{array}{l}2.55 \\
2.67 \\
0.12\end{array}$ & $\begin{array}{r}3.50 \\
3.39 \\
-0.11\end{array}$ & 0.139 \\
\hline $\mathbf{H}$ & $\begin{array}{l}x_{1} \\
x_{2} \\
x_{2}-x_{2}\end{array}$ & $\begin{array}{l}0.23 \\
0.29 \\
0.06\end{array}$ & $\begin{array}{l}0.27 \\
0.38 \\
0 \cdot 11\end{array}$ & $\begin{array}{l}0.34 \\
0.51 \\
0.17\end{array}$ & $\begin{array}{l}0.44 \\
0.86 \\
0.42\end{array}$ & $\begin{array}{l}0.75 \\
1.56 \\
0.81\end{array}$ & $\begin{array}{l}1.69 \\
2.18 \\
0.49\end{array}$ & $\begin{array}{l}2 \cdot 60 \\
2 \cdot 82 \\
0.22\end{array}$ & $\begin{array}{l}\mathbf{3 \cdot 3 7} \\
\mathbf{3 \cdot 3 7} \\
\mathbf{0 \cdot 0 0}\end{array}$ & $\begin{array}{r}4.20 \\
3.80 \\
-0.40\end{array}$ & $0 \cdot 188$ \\
\hline
\end{tabular}

extrapolations of the smooth fitted curves were necessary. The variation may therefore be artificial. Extrapolation is also involved in the lower part of category 0 . On the other hand each pit shows a maximum of this measure of progression in category

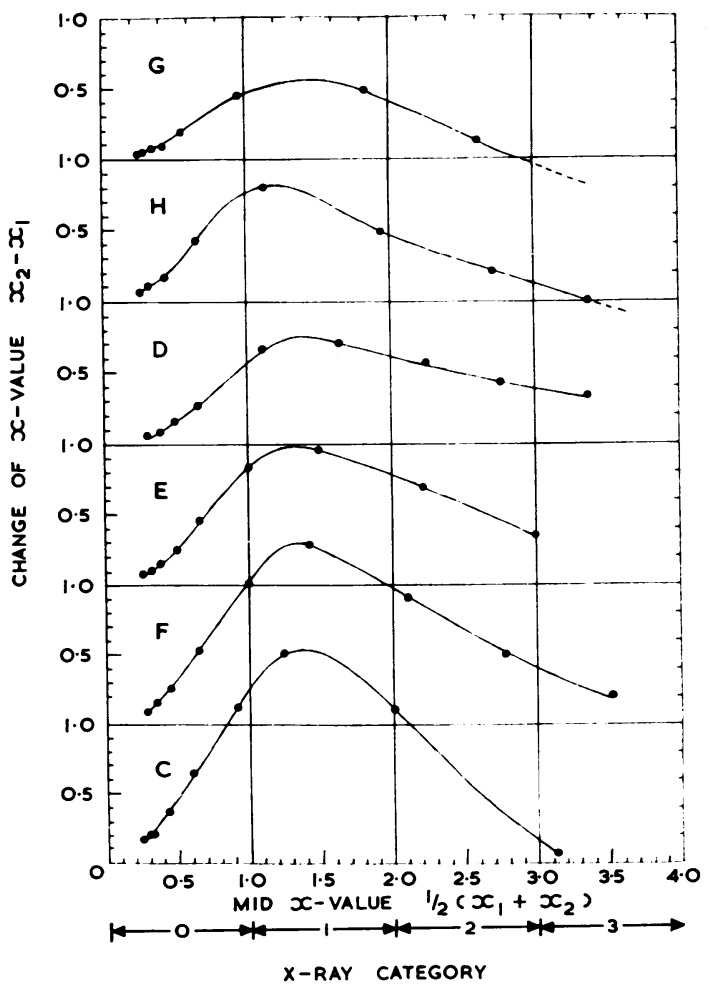

1 and a lower amount in category 2 , and over these regions the data are most reliable. Also the corrections for radiographic technique are smaller in the middle of the range. The relative heights of the curves in this central region of the continuum give a fair measure of the relative progression rates. Provided that the relative heights do not vary much from point to point an average of the amount of progression, say from the 10th to the 90th percentile, can be taken as a rough measure by which the progression in different pits can be compared.

2. On a Uniform Progression Scale, the w-scale.Fig. 4 shows apparent variation from point to point of the continuum; at the other extreme, as has been discussed earlier, we can assume that progression should in fact be equal everywhere, when measured on the appropriate scale. On the $x$-ray continuum scale it is clear that it is greatest near the middle of category 1 , declining in category 2 . This decline is least marked in pit D. Excluding D, the common shape was estimated by averaging the five curves, after first scaling them up or down so that their heights at $x=1.5$ were unity; in order to obtain a uniform progression scale the region where the progression was greatest, near 1.5 , must be closed in and the extreme regions on either side opened out.

FIG. 4-Amounts of progression in six of the pits, plotted as in Fig. 3, after approximate corrections to the data for uneven distribution of films of different radiographic quality within each survey in each pit. Each dot corresponds to $10 \%$ in ranking order of abnormality half-way between the surveys, $e . g$. in pit $E$ the progression of the $40 \%$ man in this order $(40 \%$ had less simple pneumoconiosis, $60 \%$ more) was 0.25 . The order of the pits from above down is that of increasing peak progression. The 90 th percentiles in pits $G$ and $H$ are negative and have been omitted. 
The average progression for small intervals in the new $w$-scale can be made equal all along it; this is not difficult mathematically and such a scale is uniquely defined in terms of the old one (see Appendix B) in all essentials. Only the relative spacing of points on this scale matters; the origin can be chosen at will by adding a constant factor to all the points; similarly they can all be multiplied by a constant factor. In the $w$-scale (Table 5), the choice of origin and constant factor has been made so that the points $x=1$ and $x=2$ are left unchanged.

TABLE 5

UNIFORM AVERAGE PROGRESSION SCALE

\begin{tabular}{c|c}
\hline Ordinary $\underset{x}{X}$-ray Scale & Uniform $\underset{w}{\text { Progression Scale }}$ \\
\hline 0 & -20 \\
0.25 & -1.238 \\
0.50 & $0 \cdot 146$ \\
0.75 & 0.674 \\
1.00 & 1.000 \\
1.25 & 1.256 \\
1.50 & 1.491 \\
1.75 & 1.731 \\
2.00 & $2 \cdot 000$ \\
2.25 & $2 \cdot 324$ \\
2.50 & 2.745 \\
2.75 & 3.329 \\
3.00 & 4.200 \\
3.25 & 5.605 \\
3.50 & $8 \cdot 012$ \\
3.75 & 12.704 \\
\hline
\end{tabular}

On this $w$-scale the estimates of progression, for different percentiles for each distribution in one pit, still vary slightly; the variations mainly correspond to deviations in shapes of the six curves in Fig. 4 from the mean shape. Instead of showing these variations by means of a figure like Fig. 4, Table 6 shows the observed progression at those points of the continuum corresponding to the 40th, 50th, 60th, 70th, and 80th percentiles of the populations of men. In pit $G$ the amount of abnormality of the 40th percentile in the second survey was still below $x=\frac{1}{2}$, so no entry has been made. In pit $\mathrm{H}$ the 80 th percentile in the first survey was already in category 3 , and this has been omitted also. In this way no large extrapolations have been included.
The most reliable figures for each pit are again those at and just above the $50 \%$ point, and to give an average amount of progression for each pit its value at the 50th, 60th, and 70th percentiles has been averaged in the last column but one. The unit throughout is the width of category 1 , so that for example the average amount of progression in pit $\mathbf{G}$ is half the range of abnormality represented by the difference between films on the 0-1 and 1-2 boundaries. If then this progression is due to some external factor or "dose" that can be defined quantitatively, and if the amount of progression is proportional to the dose, these averages give the relative doses for the six pits.

On the $x$-scale measure of progression displayed in Fig. 4, there is no natural method of summarizing progression, since ex hypothesi progression is different at different points of the continuum. At the same time the relative amounts of progression in different pits can be arbitrarily compared by carrying out the same procedure of averaging the 50th, 60 th, and 70th percentile values. The last column of Table 6 shows the results; the unit is again the width of category 1 . The figures are all smaller than on the $w$-scale, but the rank order of the pits is the same.

3. On the Dust Retention Scale, the X-scale.Finally we turn to the progression scale, $X$, introduced by Rivers and Wise (1960) (Table 6). This is such that equal increments by weight of dust retained in the lungs (siliceous material counting nine times as much as coal) cause equal amounts of $x$-ray change at all points on the continuum. By using this scale we can estimate the actual amount of progression as an increment of dust, for a known proportion of each population.

The relation between the $X$ and $x$-scales is given in Table 7. Progression at each percentile was derived in the same way as before by recording the difference in $X$-values corresponding to the same percentile in the two surveys. The results are shown in Fig. 5 and in Table 8.

TABLE 6

PROGRESSION MEASURED ON UNIFORM PROGRESSION SCALE, THE $w$-SCALE, AT THE 40th TO 80th PERCENTILES

\begin{tabular}{|c|c|c|c|c|c|c|c|}
\hline \multirow{2}{*}{ Pit } & \multicolumn{5}{|c|}{ Percentile } & \multirow{2}{*}{$\begin{array}{c}\text { Mean of } \\
50,60 \text {, and } 70\end{array}$} & \multirow{2}{*}{$\begin{array}{c}\text { Mean of } \\
\text { Same Percentiles } \\
\text { on the } x \text {-scale }\end{array}$} \\
\hline & 40 & 50 & 60 & 70 & 80 & & \\
\hline $\begin{array}{l}\mathbf{C} \\
\mathbf{D} \\
\mathbf{E} \\
\mathbf{F} \\
\mathbf{G} \\
\mathbf{H}\end{array}$ & $\begin{array}{l}1.77 \\
0.52 \\
0.72 \\
1.15 \\
-\overline{0.82}\end{array}$ & $\begin{array}{l}1.78 \\
0.71 \\
0.94 \\
1.35 \\
0.45 \\
0.87\end{array}$ & $\begin{array}{l}1.86 \\
0.80 \\
1.05 \\
1.30 \\
0.54 \\
0.55\end{array}$ & $\begin{array}{l}1.86 \\
0.82 \\
0.95 \\
1.26 \\
0.50 \\
0.59\end{array}$ & $\begin{array}{l}1.41 \\
1.29 \\
1.02 \\
1.56 \\
0.25 \\
-\end{array}$ & $\begin{array}{l}1.83 \\
0.74 \\
0.98 \\
1.30 \\
0.50 \\
0.67\end{array}$ & $\begin{array}{l}1.09 \\
0.64 \\
0.75 \\
1.07 \\
0.37 \\
0.51\end{array}$ \\
\hline
\end{tabular}

The unit is the width of category 1 , so that the mean progression in pit $\mathrm{C}$ of 1.83 is almost twice the amount of abnormality represented by the change from the 0-1 to the 1-2 boundaries. 
TABLE 7

THE DUST-RETENTION SCALE

\begin{tabular}{|c|c|}
\hline Ordinary $\underset{x}{X \text {-ray Scale }}$ & $\underset{X}{\text { Dust-retention Scale }}$ \\
\hline $\begin{array}{l}0.25 \\
0.50 \\
0.75 \\
1.00 \\
1.25 \\
1.50 \\
1.75 \\
2.00 \\
2.25 \\
2.50 \\
2.75 \\
3.00 \\
3.25 \\
3.50\end{array}$ & $\begin{array}{r}2.2 \\
3.2 \\
4.5 \\
5.2 \\
5.6 \\
6.0 \\
6.6 \\
7.3 \\
8.2 \\
9.0 \\
9.8 \\
10.6 \\
11.4 \\
12.3\end{array}$ \\
\hline
\end{tabular}

TABLE 8

PROGRESSION MEASURED ON THE DUST SCALE $X$

\begin{tabular}{c|c|c|c|c|c|c|c|c}
\hline \multirow{2}{*}{ Pit } & \multicolumn{7}{|c|}{ Percentile } & $\begin{array}{c}\text { Mean of } \\
50,60 \\
\text { and 70* }\end{array}$ \\
\cline { 2 - 9 } & 20 & 30 & 40 & 50 & 60 & 70 & 80 & \\
\hline C & 0.7 & 0.8 & 1.6 & 2.7 & 3.4 & 4.2 & 3.9 & 1.63 \\
D & 0.4 & 0.8 & 1.0 & 1.3 & 1.6 & 1.9 & 1.4 & 0.76 \\
E & 0.4 & 0.7 & 1.1 & 2.1 & 2.1 & 2.1 & 2.0 & 1.00 \\
F & 0.7 & 1.2 & 2.3 & 2.8 & 3.0 & 2.9 & 1.6 & 1.38 \\
G & 0.2 & 0.4 & 0.4 & 1.1 & 1.1 & 1.3 & 0.5 & 0.56 \\
H & 0.2 & 0.8 & 1.9 & 1.6 & 1.5 & 0.7 & 0 & 0.60 \\
\hline
\end{tabular}

*Since on this scale category 1 stretches from $5 \cdot 2$ to $7 \cdot 3$, i.e. is $2 \cdot 1$ units long, these means have been divided by $2 \cdot 1$ to make them comparable with those in Table 6.

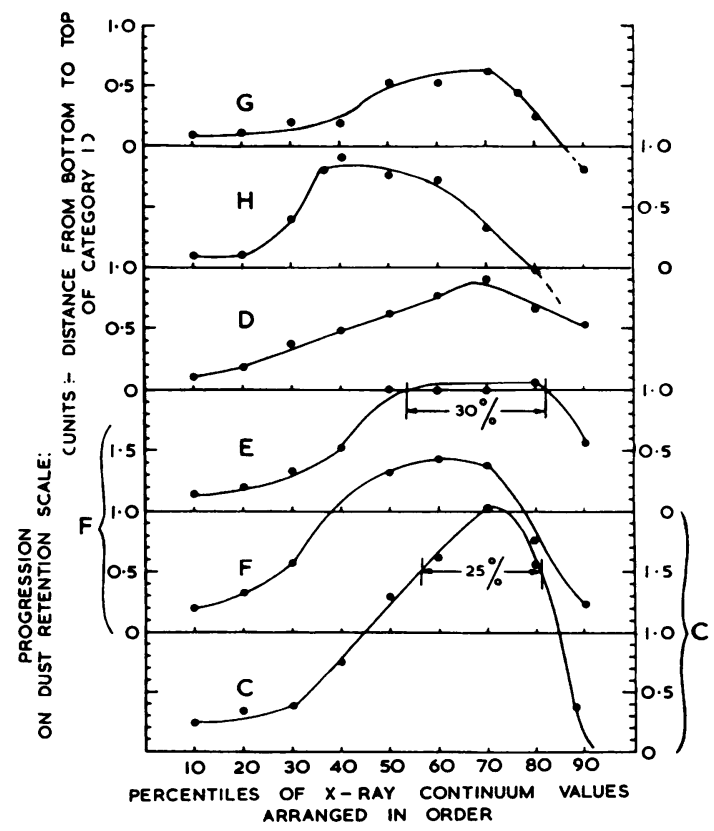

Fig. 5.-Amounts of progression, measured in the dust-retention scale of Table 9, and plotted against the percentage ranking halfway between the surveys. In contrast to Fig. 4, equal spacing along the abscissae now corresponds to equal proportions of the pit populations.
In Fig. 5, in contrast to Fig. 4 , we have spaced the percentiles equally along the abscissa. In this way we can see at once what proportion of individuals in a pit have progressed by the amounts plotted. The position on the continuum where the progression has taken place can be found from Fig. 4, or from Tables 4 or 8 . For example, in pit $\mathbf{H}$ the percentiles between 32 and 66 indicate progressions of more than $\frac{1}{2}$, that is $66 \%-32 \%=34 \%$ of this smoothed out population. From Fig. 4 we see that the corresponding middle values, the amounts of simple pneumoconiosis half way between the surveys, lie between 0.5 (between the $3 \mathrm{rd}$ and 4 th points on curve $\mathrm{H}$ ) and 2.4 (between the 6 th and 7 th points on this curve). Similarly Fig. 5 shows that in pit E $30 \%$ of the individuals have progressions about equal to one unit, and that in pit $\mathrm{C}$ about $25 \%$, between the 55th and 80th percentiles, have progressions of more than 1.5 , and $40 \%$ in pits $\mathrm{C}$ and $\mathrm{F}$ show progressions greater than one unit.

Compared with Fig. 4 the relative variation along the continuum is less; but there is still a pronounced maximum between the 40th and 80th percentiles. It appears that there really is a variation in the amount of progression at different points on the continuum. Although the $w$-scale provides a suitable single measure for an inter-pit comparison, it is potentially misleading to give it in isolation when describing what has happened to a whole pit population, since a varying proportion of the men may be progressing far faster than the rest. Note, however, that the average of the 50th, 60th, and 70th percentiles (Table 8, last column) still ranks the pits in the same way as do the corresponding averages on the $x$ and $w$ scales, also that their relative values are not very different on the $x$ and the $w$ scales.

Variation in Progression Among Individuals.-So far all methods of measuring progression have led to estimates appropriate to the whole group of subjects under study rather than to individuals (even though we have estimates of the smoothed variation of progression between individuals in the group we are unable to estimate their exact progressions). The available data are insufficient to do more than this, since we have not got multiple independent readings of the individuals' films. From our data we have tried to obtain a direct estimate of variation among individuals by including the side-by-side readings as if they were independent and unbiased and ignoring the effect of radiographic technique. This gives two readings of each film, and obviously rather more would in practice be necessary.

The two readings are averaged, and the results expressed on the $x$-scale. Thus two readings of category 2 indicate a mid-category subject, of 
$x$-value 2.5; one reading of 1 and one of 2 indicate a borderline subject, of $x$-value 2.00 (the procedure is equivalent to averaging category numbers and adding one-half). The average $x$-value for each survey is converted to an $X$-value on the dust-retention scale by means of Table 7, giving two numbers $X_{1}$ and $X_{2}$ whose difference, $X_{2}-X_{1}$, represents an estimate of the subject's increment of dust retained between the surveys, in terms of its radiological effect. When this is done for each subject a complete distribution of progression for each pit is obtained.

These distributions can be compared with the ones obtained from the postulate of a smooth distribution shown in Fig. 5. First they must be arranged in order of their mid-category values. These were estimated by averaging all four readings on the $x$-scale, converting this mid-survey value to an $X$-value, and arranging these $X$-values in increasing order. The corresponding $x$-values were of course in the same order. The progression of subjects with the same mid-survey value can be plotted at the appropriate percentage point. The progressions $X_{2}-X_{1}$ are again divided by $2 \cdot 1$, the width of category 1 on the $X$-scale, to make the unit of progression equal to the width of category 1 .

Fig. 6 shows the result. On the whole the individual progressions (full lines) lie below those on the smooth curves (dotted lines). This is because the side-by-side readings mostly show less progression than the separate readings, and also because no progression is recorded when all four readings are category 0 (or of course all four are any other category). At the upper end of the continuum the individual estimates for pits $\mathrm{F}$ and $\mathrm{H}$ are higher than the calculated ones. On the whole, and considering that the side-by-side readings were used in obtaining the histograms but not the smooth curves, there is fairly good agreement in shape between the distributions derived from the two very different methods. There is a definite tendency for higher progressions to occur in the middle of the continuum. Even for pit $F$, despite the disagreement at the upper end,

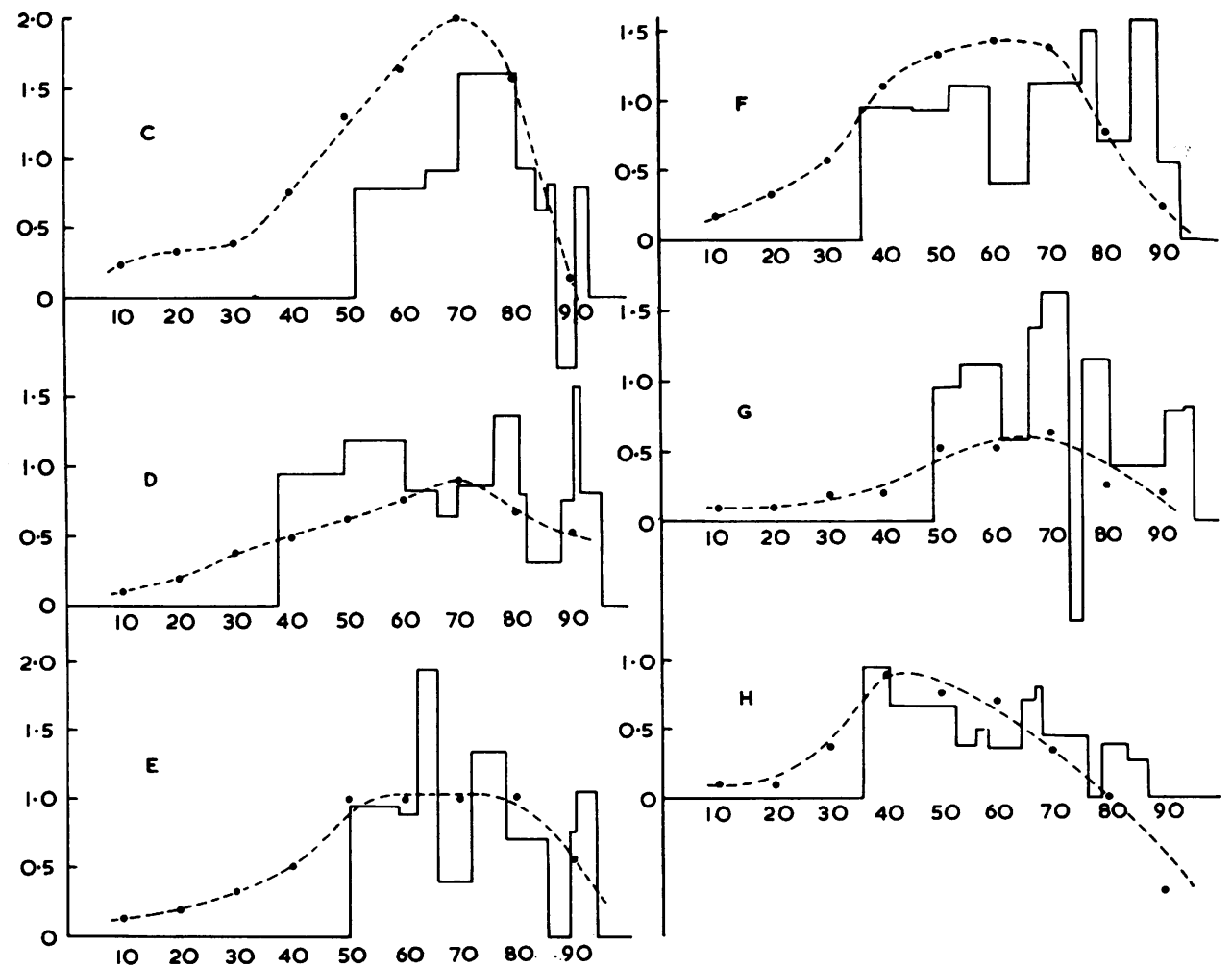

Fig. 6.-Comparison of the different estimates of progression among individuals, plotted in the same way as Fig. 5. The smooth curves are as in Fig. 5; for the block diagrams both the progressions and the mid-survey values for individuals were obtained by averaging the readings of $x$-ray categories, arranging these in order to obtain the percentage ranking for the mid-survey values and converting the first and second averages to the $x$-scale to obtain ordinates. 
the broad maximum is still to be seen, in contrast to a much narrower one for pit $\mathrm{C}$.

The Exceptional Pit C.-We recall that pit $\mathrm{C}$ was exceptional in that the average of all the separate readings was significantly greater than that for the side-by-side readings (Table 3). From Table 1 it can be seen that this arises more especially through 0 and 1 in separate readings becoming 0 and 0 in paired readings, and 0 and 2 in separate readings becoming 0 and 1 in paired readings. The complete analysis reveals a probable explanation for this. Suppose that at the time of the first survey there were many men with chest radiographs low in category 0 (cf. Table 4); by the time of the second survey many of them had progressed to points nearer the $0-1$ and the 1-2 boundaries, but there were still many more below than above the 0-1 boundary. Random observer error would then cause more 0's to be classified as 1 than 1's as 0 .

Whether or not this is the explanation, the continuum analysis suggests a large amount of progression which other methods do not reveal. The analysis of individuals shown in Fig. 6 does not suggest that the progression in pit $\mathrm{C}$ was the highest. The conclusion that very many men began low in category 0 is supported by the analysis of distribution of years underground for coal-face workers in this pit (A. L. Cochrane, unpublished). Although it is inadmissible as an argument for preferring one method of analysis more than another, it is of interest that this pit was, by general consent, by far the most dusty of the six during the relevant period.

Other Methods of Estimating Progression.Methods of estimating progression which at first sight are simpler and more obvious than ours do not rank the pits in the same way as is given by the continuum analysis, nor lead consistently to an alternative ranking. Two simple methods have been tried. The first was the mean difference of category numbers between surveys by both methods of reading (see the last column of Table 2), the second was the proportion of men in category 0 at the first survey who became category 1 or 2 at the second. Table 9 gives the four estimates-two by each method of reading - for each pit. The only consistent feature seems to be that pit $F$ is given a high progression rate three times, although in one of the three it is only just ahead of D. This Table also shows the average amounts of progression on the three scales, $x, w$, and $X$, and the rank order of each. For completeness, estimates for pits $\mathbf{A}$ and $\mathbf{B}$ have been added, uncorrected for effects of technique, and less reliable than those for the other pits. Their rank orders are however clearly 7 th and 8 th respectively.

Predicting Progression.-The progressions in all the six pits analysed in detail seem large for a time interval that is so small compared with a miner's working life underground. In most pits this form of analysis would need a longer time interval, but not one so long that many of the coal-face workers leave the pit between the first and last survey.

In any case we would like to know how the distribution of prevalence is likely to change, and what will happen to individuals if they remain exposed to the same environment. This assumption might be reasonable for short periods of the order of a year or two. Then a prediction of the progression can be quite easily obtained using the dust-retention scale and Table 8. In pit $D$ for example the 40th percentile changed from 3.7 to 4.7 in two and a half years; after one more year it should increase further to about $5 \cdot 1$.

We have seen that in each pit during the particular period of two and a half years between the surveys the men in category 1 accumulated more dust than

TABLE 9

COMPARISONS OF DIFFERENT MEASURES OF PROGRESSION; MAGNITUDES AND RANK ORDER

\begin{tabular}{|c|c|c|c|c|c|c|c|c|}
\hline \multirow[b]{2}{*}{ Pit } & \multicolumn{2}{|c|}{ Separate Readings } & \multicolumn{2}{|c|}{ Side-by-side Readings } & \multicolumn{4}{|c|}{ Mean of 50th, 60th, and 70th Percentiles* } \\
\hline & $\begin{array}{c}\% \\
\text { Progressing }\end{array}$ & $\begin{array}{c}\text { Mean } \\
\text { Change }\end{array}$ & $\begin{array}{c}\% \\
\text { Progressing }\end{array}$ & $\begin{array}{c}\text { Mean } \\
\text { Change }\end{array}$ & $\begin{array}{c}\text { Ordinary } \\
x \text {-ray } \\
\text { Scale } \\
x\end{array}$ & $\begin{array}{c}\text { Uniform } \\
\text { Progression } \\
\text { Scale } \\
w\end{array}$ & $\begin{array}{l}\text { Dust } \\
\text { Retention } \\
\text { Scale } \\
X\end{array}$ & $\begin{array}{c}\text { Rank } \\
\text { (same on each } \\
\text { scale) }\end{array}$ \\
\hline $\begin{array}{l}\mathbf{A} \\
\mathbf{B} \\
\mathbf{C} \\
\mathbf{D} \\
\mathbf{E} \\
\mathbf{F} \\
\mathbf{G} \\
\mathbf{H}\end{array}$ & $\begin{array}{rr}16.4 & (7) \\
4 \cdot 6 & (8) \\
31.3 & (3) \\
40.0 & (2) \\
24 \cdot 1 & (5) \\
40.2 & (1) \\
20.4 & (6) \\
25 \cdot 3 & (4)\end{array}$ & $\begin{array}{l}0.122 \text { (7) } \\
0.030 \text { (8) } \\
0.345 \text { (4) } \\
0.518 \text { (2) } \\
0.354 \text { (3) } \\
0.547 \text { (1) } \\
0.280 \\
0.226 \text { (5) }\end{array}$ & $\begin{array}{ll}17.0 & (5) \\
14.3 & (8) \\
20.0 & (2) \\
23.1 & (1) \\
16.4 & (6) \\
19.7 & (3) \\
19.6 & (4) \\
15.0 & (7)\end{array}$ & $\begin{array}{l}0.144 \text { (7) } \\
0.091 \text { (8) } \\
0.184 \text { (5) } \\
0.205 \text { (4) } \\
0.207 \text { (3) } \\
0.236 \text { (1) } \\
0.220 \\
0.155 \text { (6) }\end{array}$ & $\begin{array}{c}0.28 \\
0 \text { to } 0.1 \\
1.09 \\
0.64 \\
0.75 \\
1.07 \\
0.37 \\
0.51\end{array}$ & $\begin{array}{c}0.32 \\
0 \text { to } 0.1 \\
1.83 \\
0.74 \\
0.98 \\
1.30 \\
0.50 \\
0.67\end{array}$ & $\begin{array}{c}0.41 \\
0 \text { to } 0.1 \\
1.63 \\
0.76 \\
1.00 \\
1.38 \\
0.56 \\
0.60\end{array}$ & $\begin{array}{l}(7) \\
(8) \\
(1) \\
(4) \\
(3) \\
(2) \\
(6) \\
(5)\end{array}$ \\
\hline
\end{tabular}

Percentage of category 0's at the first survey progressing to categories 1 or 2 at the second; mean changes of category reproduced from Table 2 ; Percentage of category 0 's at the first survey progressing to categories 1 or 2 at the seco
and averaged progressions on the $x, w$, and $X$ scales. Rank orders in parentheses.

*Mean of 60th, 70th, and 80th percentiles for pit A (to avoid extrapolation) uncorrected for radiographic technique. 
those men in category 2 . If this tendency continues to hold good after this particular period an individual will retain dust at a slower rate when he has reached category 2 than he did when he was in category 1. In fact the behaviour deduced from a cross-sectional study would then correctly describe the longitudinal behaviour of a group of men. This suggests that the $w$-scale is the most appropriate one for predicting progression over a long period because, on it, changes of the $w$-values of individuals within a group are independent of their position in the category scale. With the help of this scale we can describe, fairly simply but quite empirically, how a smoothed-out complete distribution of abnormality for the coal-face workers in one pit at the first survey has changed into a second distribution for the second survey. The cumulative distributions of abnormality, plotted on the $w$-scale ( \% exceeding $w$ plotted against $w$ ) for the first and second surveys of the same men in the same pit form pairs of roughly parallel curves.

TABLE 10

PREDICTION OF PROGRESSION MEASURED ON THE w-SCALE

\begin{tabular}{|c|c|c|c|c|c|c|c|}
\hline & \multicolumn{7}{|c|}{ Percentiles } \\
\hline & 30 & 40 & 50 & 60 & 70 & 80 & 90 \\
\hline $\begin{array}{c}\text { Pit C } \\
w_{1} \\
w_{2} \\
w_{3} \\
x_{3}\end{array}$ & & $\begin{array}{r}-1 \cdot 36 \\
0.41 \\
2 \cdot 18 \\
2 \cdot 16\end{array}$ & $\begin{array}{r}-0.88 \\
0.90 \\
2.68 \\
2.46\end{array}$ & $\begin{array}{r}-0.40 \\
1.46 \\
3.32 \\
2.75\end{array}$ & $\begin{array}{l}0.15 \\
2.01 \\
3.87 \\
2.92\end{array}$ & $\begin{array}{l}1.46 \\
2.87 \\
4 \cdot 28 \\
3.00\end{array}$ & $\begin{array}{l}4.66 \\
5.06 \\
5.56 \\
3.20\end{array}$ \\
\hline $\begin{array}{c}\text { Pit D } \\
w_{1} \\
w_{2} \\
w_{3} \\
x_{3}\end{array}$ & $\begin{array}{r}-0.08 \\
0.35 \\
0.78 \\
0.80 \\
\end{array}$ & $\begin{array}{l}0.23 \\
0.75 \\
1.27 \\
1.78\end{array}$ & $\begin{array}{l}0.73 \\
1.44 \\
2.15 \\
2.14\end{array}$ & $\begin{array}{l}1.30 \\
2.00 \\
2.70 \\
2.47\end{array}$ & $\begin{array}{l}1.94 \\
2.76 \\
3.58 \\
2.84\end{array}$ & $\begin{array}{l}2 \cdot 89 \\
4 \cdot 18 \\
5.47 \\
3 \cdot 20\end{array}$ & $\begin{array}{r}5.40 \\
8.70 \\
12.00 \\
3.70\end{array}$ \\
\hline $\begin{array}{c}\text { Pit E } \\
w_{1} \\
w_{2} \\
w_{3} \\
x_{3}\end{array}$ & & $\begin{array}{r}-0.29 \\
0.43 \\
1.15 \\
1.15\end{array}$ & $\begin{array}{l}0.00 \\
0.94 \\
1.88 \\
1.87\end{array}$ & $\begin{array}{l}0.37 \\
1.42 \\
2.47 \\
2.34\end{array}$ & $\begin{array}{l}1.03 \\
1.98 \\
2.93 \\
2.59\end{array}$ & $\begin{array}{l}1.87 \\
2.89 \\
3.91 \\
2.93\end{array}$ & $\begin{array}{l}3.52 \\
5.02 \\
6.52 \\
3.35\end{array}$ \\
\hline $\begin{array}{c}\text { Pit F } \\
w_{1} \\
w_{3} \\
w_{3} \\
x_{3} \\
\end{array}$ & $\begin{array}{r}-0.58 \\
0.35 \\
1.28 \\
1.29\end{array}$ & $\begin{array}{r}-0.26 \\
0.89 \\
2.04 \\
2.04\end{array}$ & $\begin{array}{l}0.14 \\
1.49 \\
2.84 \\
2.54\end{array}$ & $\begin{array}{l}0.75 \\
2.05 \\
3.35 \\
2.76\end{array}$ & $\begin{array}{l}1.63 \\
2.89 \\
4.15 \\
2.99\end{array}$ & $\begin{array}{l}2 \cdot 80 \\
4 \cdot 36 \\
5.92 \\
3 \cdot 30\end{array}$ & \\
\hline $\begin{array}{c}\begin{array}{c}\text { Pit G } \\
w_{1} \\
w_{2} \\
w_{3} \\
x_{3}\end{array} \\
\end{array}$ & & & $\begin{array}{l}0.04 \\
0.49 \\
0.93 \\
0.95\end{array}$ & $\begin{array}{l}0.64 \\
1.18 \\
1.72 \\
1.74\end{array}$ & $\begin{array}{l}1.56 \\
2.06 \\
2.56 \\
2.39\end{array}$ & $\begin{array}{l}2.85 \\
3 \cdot 10 \\
3.35 \\
2.76\end{array}$ & \\
\hline $\begin{array}{c}\text { Pit H } \\
w_{1} \\
w_{2} \\
w_{3} \\
x_{3}\end{array}$ & $\begin{array}{r}-0.42 \\
0.19 \\
0.80 \\
0.85\end{array}$ & $\begin{array}{l}0.00 \\
0.82 \\
1.64 \\
1.60\end{array}$ & $\begin{array}{l}0.67 \\
1.54 \\
2.41 \\
2.31\end{array}$ & $\begin{array}{l}1.67 \\
2.22 \\
2.77 \\
2.51\end{array}$ & $\begin{array}{l}2.95 \\
3.54 \\
4.13 \\
2.99\end{array}$ & & \\
\hline
\end{tabular}

The first two rows give percentiles $\left(w_{1}\right.$ and $w_{2}$ ) calculated from the smooth distributions fitted to the observed ones, after allowing for "bad" film technique. The third row gives the predicted percentiles $w_{3}$, corresponding to the same amount of progression from the time of the second survey as between the first and second surveys $\left(w_{3}=\right.$ $\left.w_{2}+w_{2}-w_{1}\right)$. The fourth row gives the corresponding percentiles $\left(x_{3}\right)$, converted back to the $x$-scale.
In Table 10 are given the percentiles for a predicted third prevalence distribution in the $w$-scale and the corresponding values in the original $x$-scale at a time such that the further progression on the $w$-scale was equal to that between the 1st and 2 nd surveys (i.e. $w_{3}-w_{2}=w_{2}-w_{1}$ ). In four of the pits more than half of the men would have reached category 2.

Estimates of the Rate of Progression after the Second Survey.-A third survey was carried out five and a half years after the second, mainly for investigating progressive massive fibrosis. Many miners left the coal-face in the interval between the second and third surveys and not every miner who was still on the coal-face had another radiograph taken. Hence we were unable to verify the predicted prevalence distributions shown in Table 10. Instead of this, we have compared the prevalence distributions for the men in each pit who were on the coal-face all the time.

The progressions between the first and second and between the second and third surveys were again estimated by comparing cumulative distributions. These again are expressed in the uniform progression $(w)$ scale, because this made most of these distributions approximately parallel. Fig. 7 shows each group of three accumulated distributions of prevalence for five of the pits. (In pit $G$ there were only three coal-face workers in all three surveys, and pit $C$ was not in the third survey.) In pits $A$ and $H$ some retrogression shows up between the first and second survey, but the numbers involved are very small; in pit $\mathbf{H}$ the plots of the first and third surveys are nearly parallel while the second distribution is discrepant, and in the other pits the trend is reasonably clear.

Table 11 gives the estimates of mean progression in the $w$-scale. In these smaller populations, the progression between the first two surveys might not be the same as for the complete populations, since the number still on the face five and a half years later would be by no means a random sample of the whole. However it seems that as far as their average progressions were concerned they were fairly representative; the estimates of Table 11 agree quite well with those of Table 6 . Between the 2nd and 3rd survey adequate numbers were available only for pit $D$. There it was clear that the progression rate per year remained about the same in the fiveand-a-half-year period as in the first two-and-a-halfyear period. In pits $\mathrm{E}, \mathrm{F}$, and $\mathrm{H}$ on the other hand, although the numbers of men were smaller, for these men at least the progression rate per year had slowed up appreciably. In pit $\mathbf{A}$ the rate was small and possibly remained about the samc. 
FIG. 7.-Distributions of radiological abnormality for workers who were on the coal-face in all three surveys, $1,2,3$, plotted cumulatively as percentages exceeding a given amount of abnormality on the $w$-scale. This illustrates the approximately parallel shift and the progressions after two and a half years and after eight years. The $x$-ray categories and their boundaries are shown also.

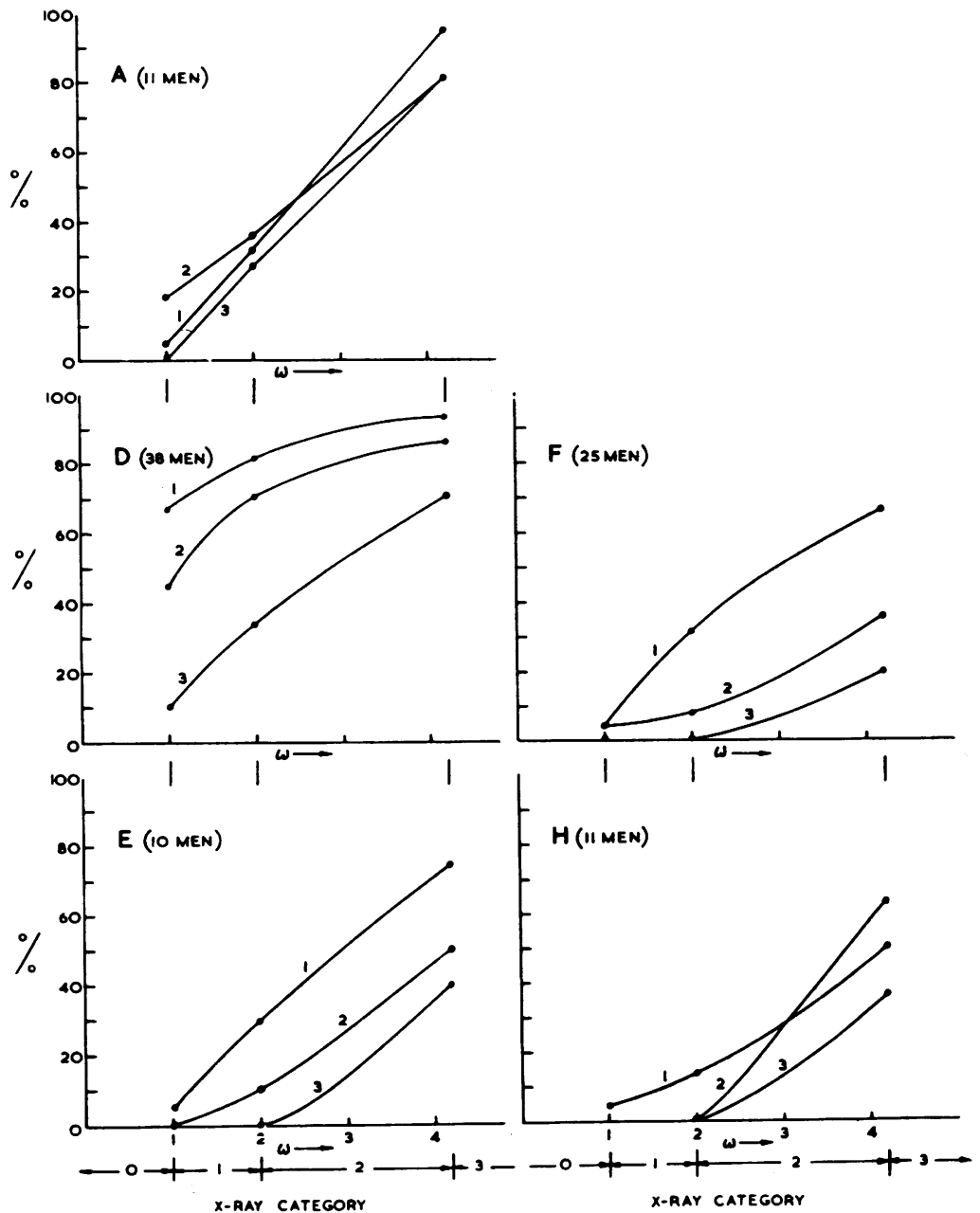

TABLE 11

ESTIMATED PROGRESSIONS BETWEEN THE 1st AND 2nd SURVEYS (TWO AND A HALF YEARS APART) AND BETWEEN 2nd AND 3rd SURVEYS (FIVE AND A HALF YEARS APART) MEASURED ON THE UNIFORM PROGRESSION (w) SCALE, FOR WORKERS WHO WERE ON THE COAL-FACE THROUGHOUT THE TWO PERIODS

\begin{tabular}{l|c|c|c}
\hline \multirow{2}{*}{ Pit } & $\begin{array}{c}\text { Number } \\
\text { of Men }\end{array}$ & $\begin{array}{c}\text { Petween 1st and } \\
\text { 2nd Surveys }\end{array}$ & $\begin{array}{c}\text { Between 2nd and } \\
\text { 3rd Surveys }\end{array}$ \\
\hline A & 11 & $\begin{array}{c}0 \text { to } 0.2 \\
\text { (unreliable) }\end{array}$ & 0.2 to 0.4 \\
D & 38 & 0.8 & 1.5 to 2.2 \\
E & 10 & 0.8 to 1.2 & 0.6 \\
F & 25 & 1.0 to 1.8 & 1.1 \\
H & 11 & $\begin{array}{c}0.5 \text { to } 1.0 \\
\text { (unreliable) }\end{array}$ & $\begin{array}{c}0 \text { to } 1.0 \\
\text { (unreliable; } 0.85 \\
\text { between 1 Ist and 3rd } \\
\text { surveys) }\end{array}$ \\
\hline
\end{tabular}

The Continuum of Radiological Abnormality.Two main principles have been suggested as a basis for analysing and estimating progression. The first is that of a smooth continuous distribution of abnormality among subjects in a naturally occurring group-in this case populations of coal-face workers in a single pit. However precise or imprecise are the measurements on an individual, more information about him is gained by analysing the group to which he belongs. This principle can be supported by pointing out the universality of such distributions wherever characteristics which can be measured have been studied in population samples. Usually a detailed study reveals irregularities over and above those due to pure chance; for example a whole subgroup of miners might go on to the coal-face at the 

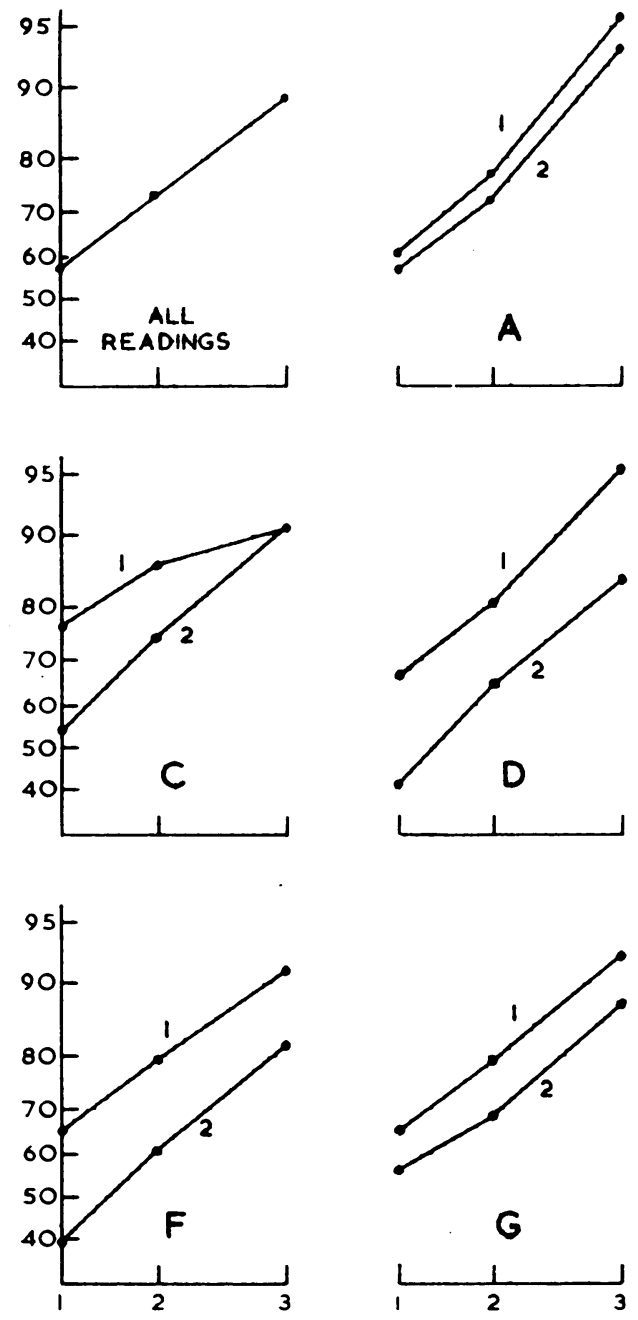

same time. But most variation in biological populations arises from a superposition of several different causes of variation, each of which by itself would lead to systematic deviations from the smooth curve, but which, working in different directions, produce in effect random variation about a smooth curve. It is the smoothness that is the important part of the assumption; we can obviously draw smooth curves through the points plotted in Fig. 8, for example, and they are nearly straight lines; another type of function fitted to the distributions of the categories $0,1,2$, and 3 might yield different extrapolated distributions of true abnormality within categories 0 and 3, but the interpolated distributions of true abnormality within categories 1 and 2 would be nearly the same.

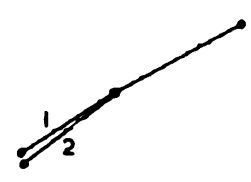

Fig. 8.-Accumulated percentages, plotted on a normal probability scale, in the distribution of $x$-ray categories from separate readings, for each pit and survey. The percentage of category 0 's is plotted at $y=1$; that of 0 's and 1 's at $1 \cdot 85$, that of 0 's, 1 's, and 2 's at $y=3$. First survey on the right, second on the left. The top left figure gives the corresponding distribution of all category readings by both methods.
The second principle is that of ranking the smoothed distributions in order of abnormality at the time of the two surveys, and assuming that the distribution of progression is more or less what it would be if all individuals stayed in the same order. This is an unusual device, but it seems an allowable one for obtaining information about differences between measurements on a very coarse scale. Moreover it may be practicable to test it directly. The experiment has been tried of arranging a certain number of films from the same pit and survey in order of abnormality (A. L. Cochrane, unpublished), and this could be done, but is technically difficult; if it were tried with the films of two surveys of the same men, the actual variations in rank order could be studied. 
Both these principles rest upon a third one, namely that there is no sharp distinction between individuals in one category of simple pneumoconiosis and the next one. It is because of this that averaging observers' separate readings on the same film should give a better estimate of the true amount of abnormality than either their separate readings or their agreed readings. In the same way, any analysis that regards a change, say, from category 1 to category 2 as a discrete event, throws away information. Methods of relating dose to an all-or-nothing response have become well established in biological research, but they should not be adopted unless it is impossible to establish a quantitative scale of response.

Transformations of the X-ray Continuum Scale.The two transformations of the $x$-ray category scale do not simply provide different measures of progression but serve different purposes. By using the uniform progression scale $(w)$, the change undergone by a whole group of people is described more simply than before, as an approximately parallel shift of an accumulated distribution of abnormality. Problems underlying such scale changes are liable to arise whenever stages of growth are marked by numbers and an organism passes through each stage in turn. It is very useful to obtain, if possible, a scale in which the rate of growth is uniform. This whole approach is still relatively novel; methods of making good use of follow-up and growth statistics have not been studied nearly enough.

Our uniform progression scale was derived from the data from five out of the eight pits. The dustretention scale, in contrast, uses a separate series of lungs and depends upon an assumption about the true nature of radiological change in simple pneumoconiosis, namely that this is mainly caused by dust being retained permanently in the lungs. The analysis by Rivers et al. (1960) certainly seems to support this, provided the composition of the dust is allowed for. The scale they derived is by no means perfect, but it should be possible to improve it when enough additional data have been collected and analysed.

The Rapid Progression Across Category 1.-The main finding from the use of the dust-retention scale is that there is a real and systematic variation of progression within one group of men when they have different degrees of simple pneumoconiosis; in particular progression, not only of radiological abnormality but also of dust retained in the lungs, was faster than average among those who were in category 1 midway between the surveys.

There are several possible interpretations of this and it is important to distinguish between them. One reasonable explanation is that this group was made up of men doing a particular sort of work which entailed greater dust exposure than the average. On the other hand the men in this group might have retained more dust because they adopted a faster rate of working or because they differ in the amount of dust that reaches or is retained in the lungs. In each case it is necessary to assume that after reaching category 2 they change their place or manner of working and so progress less fast, perhaps because they feel less fit. Although studies of lung function have revealed no very consistent association with $x$-ray category in simple pneumoconiosis, the possibility remains that men in the higher categories began their working life with above average level of performance and have materially declined.

It is essential to detect and allow for this kind of variation in estimating safe concentrations of airborne dust. From long-term studies, concentrations can be determined which from quantal dose response curves (Roach, 1953; Ashford, 1958; Fay and Ashford, 1961) would ensure that only a small proportion of men develop simple pneumoconiosis in a given time. Such concentrations would be an incomplete specification of safety; the proportion who still develop the radiological signs might not be due to random variations of exposure but to identifiable peculiarities of some individuals. Unnecessarily rigorous standards would be laid down for the majority, yet incomplete protection would be given to the few.

Techniques of Radiography and Methods of Film Reading.-The bias found in side-by-side readings was unexpected, but is not altogether surprising. The problem of reading pneumoconiosis is different in many ways from other problems of radiological diagnosis. Commonly a diagnosis of abnormality rests partly on preconceived standards, but mostly on comparison of normal and affected parts of the same organ. In pneumoconiosis the reading must be based entirely on external standards, such as the standards of the I.L.O. classification, and any process of comparison within the subject can only lead to deviations from the external standards.

The effect of variations in radiographic technique revealed in this material are discussed more fully in another paper (Wise and Oldham, 1963). They cannot be taken as firmly established, but since they suggest that serious biases are possible further work is evidently essential. It will appear that rigorous standardization and control of radiographic technique is even more important than has previously been supposed.

The Numerical Estimates of Progression.-Little 
further comment need be made on the progression measurements themselves which are unreliable in detail but probably correct in general. It is clear that some of the men were progressing rapidly; the estimate for three of the pits was more than 0.4 of category 1 per year for about $30 \%$ of the men. This is faster than was found for any of the lungs analysed by Rivers et al (1960). On the other hand this cannot be put in perspective without knowledge of the dust exposures of these rapidly progressing men.

A rough impression of the dustiness of different pits has been given by S. A. Roach (unpublished data). Pit $\mathrm{C}$, as already discussed, is known to be extremely dusty; the next in order were $\mathrm{D}, \mathrm{F}$, and $\mathrm{H}$ which are believed to be about the same, while A, B, $\mathrm{E}$, and $\mathrm{G}$ were thought to be considerably less dusty. According to our analysis the progression in $\mathrm{A}$ and $B$ is very low, $G$ is the next lowest, $D$ and $H$ come next, and $\mathrm{E}$ is third from the top. Pit $\mathrm{E}$ is thus the only one for which the progression ranking is appreciably different from the approximate dust ranking. This should not be overstressed, for the dust data at the time were probably much less reliable than the $x$-ray readings. It is very desirable in any case that doses and responses should be estimated independently of one another.

Correlation of Progression with Dust Exposure.Ashford (1959b) and Fay and Ashford (1961) have made valuable contributions to the problems of estimating exposures quantitatively, and of combining different exposures received by one man. They have used these results successfully to relate exposures of different kinds, over long periods, to prevalence distributions for some pit populations. Their proposed measure of response, i.e. a change in the amount of simple pneumoconiosis (radiological abnormality) due to exposure to respirable dust, appears to be based on observed distributions of categories of simple pneumoconiosis in particular pit populations, and on a postulated distribution of responses of individuals to a given dose. It is assumed that this distribution on a transformed $x$ ray category scale is Gaussian with a variance that is independent of the level of dose. Then the observed proportion of men with say category 2 or more is expressed on this scale in the usual way for quantal response analyses, as a normal deviate. Previously Ashford (1959a) (see also Fay and Ashford, 1960) had claimed that the same scale could be used to describe observer error, i.e. if an observer estimates that the amount of abnormality is $y+\delta$ when it is really $y$, then the observer error $\delta$ is distributed normally with zero mean and variance independent of $y$, i.e. of the true position on the scale of abnormality.
It is certainly worth while to take advantage of regularities in the data, whether these are fortunate accidents or have a physical or physiological meaning (we have done this with our normalizing transformation defined in Appendix $\mathbf{A}$ and again in deriving the $w$-scale), but it is essential to have some evidence that the regularities exist. We think it is by no means certain that the observer error scale and normalizing prevalence scales are identical in the cases quoted by Ashford, since there appear to be systematic deviations between observed and expected frequencies (Fay and Ashford, 1960, Table 5); but the fit may be good enough despite this to provide a convenient working rule. More important still is that there is very little evidence on the nature of individual variations in response to a constant dose. We have shown that there are systematic variations in progressions in which the men concerned might have similar exposures, and superposed on these averaged progressions there can be fluctuations in the responses of individuals, but these should have only slightly influenced our estimates of averaged progression. In the progression analysis outlined by Fay and Ashford (1961), the observed response is related to the proportions of men changing their category between surveys (except that category 3's are counted with category 2 's); in fact for the overall distribution of pairs of categories, for the same man in two surveys, the percentages of changing categories are small and these percentages therefore correspond to tail areas of the frequency curves for the distribution of responses. When such a tail area is converted into a normal deviate the accuracy of the result is clearly very sensitive to what is assumed about the type of variation and its magnitude. The answers obtained seem to depend too much upon initial assumptions of this kind.

We have tried to utilize much more information by considering how a whole prevalence distribution changes. For example we do not see how the exceptional properties of pit $\mathrm{C}$ in our study would be shown up by a quantal response analysis except possibly from a small but higher than expected number of progressions by two categories. In other words a quantal analysis may not be sensitive enough to distinguish between different hypotheses about causes of simple pneumoconiosis and its progression. Moreover it only answers one of the two most important questions. We are interested not only in how many men progress but also in how much they progress.

In our detailed quantitative analysis we made little use of averaged category readings, but this could easily be done on better data. The more $x$-ray technique improves, the more profitable it 
should be to have subdivisions of the $x$-ray scale, although it would be inadvisable to try to define them by standard films. Fay and Ashford (1960) have concluded that such averaging would be misleading when applied to their data, in which two readings were by one observer and one by another. On the other hand Rivers and Wise (1960) used it with success when they had groups of four independent readings (but each by two pairs of observers) more or less on an equal footing.

Rivers et al. (1960) also have a little indirect evidence on the variability of an individual's progression, measured on their dust scale as the rate of increase of abnormality per year. In their 45 cases this appears to be log-normally distributed (Table 11). This variability has, of course, two sources, that of the exposure to respirable dust and that of individual responses.

The validity of measuring doses on a log scale also needs to be studied; it is well established for truly quantal responses, but needs more justification in this problem than it has yet received. In the same 45 cases, Rivers et al. (1960, Table 3) found that the total weight of dust retained in one lung was not proportional to the number of years $T_{\mathrm{G}}$ of exposure, nor to $\log T_{\mathrm{G}}$, but was somewhere between the two. However in a large group of men (371) in similar occupations underground Fay and Ashford 1961 found a surprisingly simple relation between the proportions of men with categories 1 or more, and 2 or more and the logarithm of the number of years of exposure; the two plots were linear and parallel on a probit scale.

Various studies, then, need to be co-ordinated. The information provided by these large-scale prevalence studies should be used in investigating progression, and the principles given in this paper should be further tested in these more extensive studies. Perhaps we should point out that all our methods of analysis could be improved in detail when applied to fuller and more precise data. We should also utilize the information provided by men leaving the coal-face between surveys.

No one who has tried to find a correlation between radiological abnormality and a measure of dust exposure has failed to do so; no one has as yet succeeded with the far more difficult task of choosing the most meaningful measure of radiological abnormality and using this to choose between alternative hypotheses about its cause.

This work was begun some time ago at the Pneumoconiosis Research Unit. For part of the time during which it was being completed one of us (M.E.W.) was in receipt of a personal grant from the Medical Research Council. Professor A. L. Cochrane and Dr. W. E. Miall read the radiographs. We should like to thank Professor Cochrane for providing us with much unpublished material, Mr. W. H. Roberts for drawing the figures, and Dr. J. C. Gilson for much detailed criticism and advice.

\section{REFERENCES}

Ashford, J. R. (1958). Biometrika, 45, 74

- (1959a). Applied Statistics, 8, 168

(1959b). Biometrics, 15, 573.

(1960). Brit. J. industr. Med., 17, 293.

Carpenter, R. G., Cochrane, A. L., Gilson, J. C., and Higgins, I. T. T (1956). ibid, 13, 166 .

Cochrane, A. L. (1951). In The Application of Scientific Methods to Industrial and Service Medicine (Medical Research Council: Conference Proc.) p. 97. H.M.S.O., London.

(1962). Brit. J. industr. Med., 19, 52.

-, Carpenter, R. G., Clarke, W. G., Jonathan, G., and Moore, F. (1956). ibid., 13, 177.

- Thomas, J., and Moore, F. (1963). In the press.

Davies, I., Chapman, P. J., Rae, S., Rinsler, A. H., and Williams, M. H. C. (1956). Brit. J. industr. Med., 13, 231.

Higgins, I. T. T., and Thomas, J. (1961). Brit. J. prev. soc.

Miall, W. E., Clarke, W. G., Jarman, T. F., Jonathan, G., and

Miall, W. E., Clarke, W. G., Jarman, T. F
Moore, F. (1956). Brit. med. J., 1, 1193.

, Moore, F., and Thomas, J. (1961a). Tubercle (Lond.), 42, 64.

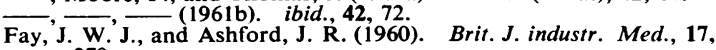
279. , (1961). ibid., 18, 175.

Fl, and Rae, S. (1959). Ann. occup. Hyg., 1, 149.

Fletcher, C. M. (1955a). Arch. industr. Hith, 11, 17. (1955b). ibid., 11, 29.

and Oldham, P. D. (1949). Brit. J. industr. Med., 6, 168. (1951), ibid., 8, 138 .

Mann, K. J., Davies, I., Cochrane, A. L., Gilson, J. C., and Mann, K. J., Davies, I., Cochrane, A. L., Gilson, J.

Gilson, J. C., Hugh-Jones, P., Oldham, P. D., and Meade, F. (1955) Spec. Rep. Ser. med. Res. Coun. (Lond.), No. 290 . H.M.S.O., London.

Hart, P. D'A., and Aslett, E. A. (1942). ibid., No. 243. H.M.S.O., London.

Higgins, I. T. T., Cochrane, A. L., Gilson, J. C., and Wood, C. H. (1959). Brit. J. industr. Med., 16, 255.

Oldham, P. D., Cochrane, A. L., and Gilson, J. C. (1956) Brit. med. J., 2, 904.

International Labour Organisation (1953). Proceedings of the Third International Conference of Experts on Pneumoconiosis, Sydney, 1950; Report of Proceedings, vol. 1, p. 130. I.L.O., Geneva. 1950; Report of Proceedings, vol.
(1959). Occup. Safety Hlth, 9, 63.

Oldham, P. D. (1962). J. chron. Dis., 15, 969

Oldham, P. D. (1962). J. chron. Dis., 15, 969.

Rivers, D., and Wise, M. E. (1960). ibid., 17, 93 .

R,, K ing, E. J., and Nagelschmidt, G. (1960). ibid., 17, 87. Roach, S. A. (1953). ibid., 10, 220.

Wise, M. E., and Oldham, P. D. (1963). ibid., 20, 145.

\section{Appendix A}

The Type of Smooth Curve Fitted to the Distributions of Radiological Categories 0, 1, 2, and 3.-The analysis in terms of these curves is given in detail in the next paper. Essentially, cumulative percentages are plotted on probability paper, for each distribution of categories to which we wish to fit a smooth curve. In this way three points are plotted, for the percentage of category 0 's, of 0 's and 1's together, and of 0's, 1's, and 2's. The percentage of 0 's is that of values of $x$ in the continuum less than 1. Similarly the percentage of 0's, 1's, and 2's is plotted at $x=3$. If the middle percentage is plotted at $x=2$, it lies, far more often than not, below the line joining the other two points. If it is plotted at $x=1.85$ the points tend to lie about a straight line. Fig. 8 shows the distributions of categories plotted in this way for each pit population and each survey.

This is equivalent to plotting the points on a $y$ scale such that $y$ takes the values $-\infty, 1,1 \cdot 85,3,+\infty$ when 
$x$ has the values $0,1,2,3,+\infty$. A mathematical transformation that achieves this and gives values of $y$ for all fractional values of $x$ is

$$
y=1.0167+0.2233 x^{2}-0.24 x^{-2},
$$

which in effect normalizes these distributions of categories.

\section{Appendix B}

How the Uniform Progression Scale was Obtained.This scale is obtained, as explained, from the average of five of the six curves in Fig. 5. This gives the amount of progression $\lambda z(x)$ across each point in the continuum, $x$-scale (here $\lambda$ is a constant depending on the population in its particular environment and on the time interval), as a ratio of the progression at $x=1 \cdot 5$.

Consider the values of $x$ within any small interval $d x$.
There will be unit progression if these values of $x$ are divided by $z(x)$. On a uniform progression scale $v(x)$ when $v$ increases to $v+d v, x$ increases to $x+d x$, provided that we put

$$
d v=d x / z(x) \text {. }
$$

It was found empirically that

$$
z(x)=c x^{2.5}(5 \cdot 75-x)^{1.5} \text { where } c \text { is a constant. }
$$

A convenient formula is

$$
\begin{aligned}
& v(x)=0.2 \int_{1}^{4 x} \frac{d x}{x^{2.5}(23-x)^{7.5}} \\
& \text { and } w=1+\frac{v(x)}{v(2),}
\end{aligned}
$$

so that $w=1$ when $x=1$ and $w=2$ when $x=2$, which gives the tabulated scale (Table 5). 